\title{
Continuum modeling of the response of a Mg alloy AZ31 rolled sheet during uniaxial deformation
}

\author{
Ana Fernández ${ }^{\mathrm{a}}$, María Teresa Pérez Prado ${ }^{\mathrm{a}}$, Yujie Wei $^{\mathrm{b}}$, Antoine Jérusalem ${ }^{\mathrm{a}, *}$ \\ ${ }^{a}$ IMDEA Materials Institute, Calle Profesor Aranguren, s/n 28040 Madrid, Spain \\ ${ }^{\mathrm{b}}$ State Key Laboratory of Nonlinear Mechanics, Institute of Mechanics, Chinese Academy of Sciences, 100190 Beijing, China
}

\section{A R T I C L E I N F O}

\section{Article history:}

Received 7 September 2010

Received in final revised form 2 May 2011

Available online 14 May 2011

\section{Keywords:}

Magnesium

Continuum model

Crystal plasticity

\begin{abstract}
A B S T R A C T
Lightweight magnesium alloys, such as AZ31, constitute alternative materials of interest for many industrial sectors such as the transport industry. For instance, reducing vehicle weight and thus fuel consumption can actively benefit the global efforts of the current environmental industry policies. To this end, several research groups are focusing their experimental efforts on the development of advanced Mg alloys. However, comparatively little computational work has been oriented towards the simulation of the micromechanisms underlying the deformation of these metals. Among them, the model developed by Staroselsky and Anand [Staroselsky, A., Anand, L., 2003. A constitutive model for HCP materials deforming by slip and twinning: application to magnesium alloy AZ31B. International Journal of Plasticity 19 (10), 1843-1864] successfully captured some of the intrinsic features of deformation in Magnesium alloys. Nevertheless, some deformation micromechanisms, such as cross-hardening between slip and twin systems, have been either simplified or disregarded. In this work, we propose the development of a crystal plasticity continuum model aimed at fully describing the intrinsic deformation mechanisms between slip and twin systems. In order to calibrate and validate the proposed model, an experimental campaign consisting of a set of quasi-static compression tests at room temperature along the rolling and normal directions of a polycrystalline AZ31 rolled sheet, as well as an analysis of the crystallographic texture at different stages of deformation, has been carried out. The model is then exploited by investigating stress and strain fields, texture evolution, and slip and twin activities during deformation. The flexibility of the overall model is ultimately demonstrated by casting light on an experimental controversy on the role of the pyramidal slip $\langle c+a\rangle$ versus compression twinning in the late stage of polycrystalline deformation, and a failure criterion related to basal slip activity is proposed.
\end{abstract}

(c) 2011 Elsevier Ltd. All rights reserved.

\section{Introduction}

Magnesium alloys are increasingly becoming very attractive materials, especially for the transport industry, due to their low density $\left(1.7 \mathrm{~g} / \mathrm{cm}^{3}\right.$ ), which is one third lower than that of Al (Easton et al., 2008; Mordike and Ebert, 2001). Systematic research efforts to understand the mechanical behavior of magnesium alloys have only been carried out for the last decade, and thus significant work must still be done before these materials can be widely commercialized (Bamberger and Dehm, 2008). In particular, at this point it is key to develop simulation models that, supported by the experimental data available, can predict of the response of $\mathrm{Mg}$ alloys under different service conditions.

\footnotetext{
* Corresponding author.

E-mail addresses: ana.fernandez@imdea.org (A. Fernández), teresa.perez.prado@imdea.org (M.T. Pérez Prado), yujie_wei@Inm.imech.ac.cn (Y. Wei), antoine.jerusalem@imdea.org (A. Jérusalem).
} 
The deformation mechanisms of $\mathrm{Mg}$ and $\mathrm{Mg}$ alloys that are operative at low strain rates have been extensively investigated over the past years (Couling et al., 1959; Kocks and Westlake, 1967; Kelley and Hosford, 1968a; Couret and Caillard, 1985; Chin and Mammel, 1970; Yoo, 1981; Vagaralia and Langdon, 1981; Zelin et al., 1992; Munroe and Tan, 1997; Agnew et al., 2001; Watanabe et al., 2001; Barnett, 2001; Agnew et al., 2003; Galiyev et al., 2003; Koike et al., 2003; Barnett, 2003; Gehrmann et al., 2005; Barnett et al., 2004a; Agnew and Duygulu, 2005; del Valle et al., 2005; Keshavarz and Barnett, 2006; Meza-García et al., 2007; Barnett, 2007; del Valle and Ruano, 2007; Al-Samman and Gottstein, 2008; Chino et al., 2008; Jain et al., 2008; Hutchinson et al., 2009; Ball and Prangnell, 1994; Lou et al., 2007). Slip in hexagonal close packed (HCP) metals may take place along the $\langle 11 \overline{2} 0\rangle(\langle a\rangle)$ direction on basal and non-basal ( $\{10 \overline{1} 0\}$-prismatic, $\{10 \overline{1} 1\}$-pyramidal) planes. Additionally, second order pyramidal $\langle c+a\rangle$ slip has also been observed on $\{11 \overline{2} 2\}$ planes (Agnew and Duygulu, 2005). Deformation is accommodated also by twinning, mainly on $\{10 \overline{1} 2\}$ and $\{10 \overline{1} 1\}$ planes.

Although widely spread values have been reported for the critical resolved shear stress (CRSS) in different slip and twinning systems (Chin and Mammel, 1970; Agnew et al., 2001, 2003; Barnett, 2003; Agnew and Duygulu, 2005; Lou et al., 2007), it is generally accepted that, for polycrystals, $C R S S_{\text {basal }}<C R S S_{\text {twinning }}<C R S S_{\text {prismatic }} \leqslant C R S S_{\text {pyramidal }}$. In agreement with this trend, earlier studies reported that slip on basal planes and $\{10 \overline{1} 2\}$ twinning (so called extension twinning) are the main deformation mechanisms during uniaxial deformation at low temperatures and low strain rates in randomly oriented Mg polycrystals of conventional grain sizes $(\sim 10-50 \mu \mathrm{m})$ (Couling et al., 1959; Kocks and Westlake, 1967; Kelley and Hosford, 1968a; Couret and Caillard, 1985; Chin and Mammel, 1970; Yoo, 1981). Non-basal slip systems are also active, albeit to a lesser extent (Koike et al., 2003; Agnew and Duygulu, 2005; Keshavarz and Barnett, 2006). The activity of different deformation modes is highly dependent on temperature, initial texture and strain rate (Gehrmann et al., 2005; Al-Samman and Gottstein, 2008; Ulacia et al., 2010; Khan et al., 2011).

Non-basal dislocations, including $\langle c+a\rangle$ ones, have been often reported as necessary accommodation for deformation in regimes of high stress concentration (Ion et al., 1982; Koike et al., 2003; Armstrong and Walley, 2008). However, the net contribution of second-order pyramidal $\langle c+a\rangle$ slip to the macroscopic strain in Mg alloys has been controversial for decades. This mechanism, if active, would provide six independent deformation modes, thus increasing significantly the ductility and the isotropy of $\mathrm{Mg}$ alloys. The activity of $\langle c+a\rangle$ slip during room temperature deformation is still a subject of debate. Due to its high CRSS, this deformation mode may only be activated when the compression axis is parallel to the $\langle 0001\rangle$ axis, as neither the basal, the prismatic nor the tensile twinning systems are favored. This occurs, for example, in the following two cases. The first case is a rolled and annealed Mg sheet with strong $\langle 0001\rangle$ texture subjected to compression along the normal direction (ND, i.e. along the c-axis of most grains). Some authors have indeed reported the occurrence of $\langle c+a\rangle$ slip under such conditions (Obara et al., 1973; Agnew et al., 2001), although others have found evidence of the accommodation of such deformation by a double twinning mechanism (Wonsiewicz and Backofen, 1967; Kelley and Hosford, 1968b). A second case is when, during compression of the same strongly texture sheet along the rolling direction (RD), twinning orients most grains with the c-axes parallel to the compression axis during the first stages of deformation. The operation of $\langle c+a\rangle$ slip during the last stages of deformation has been reported under such conditions by Yi et al. (2006). Here too, some other investigations report that strain is, instead, accommodated by the activation of other mechanisms, such as a combination of basal and $\langle a\rangle$ pyramidal slip (Mordike and Ebert, 2001), the increasing activity of basal slip (Lou et al., 2007) or the simultaneous operation of basal slip and double twinning (Kelley and Hosford, 1968b).

Such controversy is by definition difficult to solve by experimental means, requiring in situ simultaneous tracking of slip/ twin system activities and texture evolution. In this example as in many others, it is thus convenient to approach the problem with the help of crystal plasticity numerical simulations.

Despite the availability of other simulation techniques, such as dislocation dynamics (e.g. Zbib et al., 1998; Segurado et al., 2007; Groh et al., 2009; Wang et al., 2009b; Danas et al., 2010) or atomistic simulations (e.g. Wang et al., 2009a; Groh et al., 2009; Yue et al., 2010), finite element modeling (FEM) remains by far one of the only techniques able to accurately describe crystal plasticity deformation while avoiding the drastic length- and time-scale limitations plaguing the two other techniques (see for example Roters et al. (2010) for an overview of the finite element modeling applications in crystal plasticity). Note that there has been some attempts to bridge scale between techniques (Miller and Tadmor, 2002; Gao et al., 2010), but without fully alleviating these restrictions. Finally, homogenization techniques (Miehe et al., 1999; Agnew et al., 2001; Gilormini et al., 2001; Bornert et al., 2001; Liu et al., 2003; Lebensohn et al., 2004; Houtte et al., 2006; Lebensohn et al., 2007; Knezevic et al., 2008; Proust et al., 2009; Neil and Agnew, 2009; Shaffer et al., 2010) allow by definition for homogenized calculations of an overall polycrystal with a decreased computational effort, but are consequently not as flexible as FEM for microstructural evolution studies (see for example Zhao et al., 2008). Because of the problem at hand in this work, in the following we narrow down our literature review to local (nonstrain-gradient theory) and rate-independent crystal plasticity models.

If fcc and bcc crystal plasticity continuum models have already been extensively studied (Cuitiño and Ortiz, 1993; Anand and Kothari, 1996; Anand, 2004; Houtte et al., 2006; Zhao et al., 2007; Kuchnicki et al., 2008; Jérusalem et al., 2008; Roters et al., 2010; Lee et al., 2010; Liu et al., 2011; Thamburaja, 2010; Rossiter et al., 2010; Zamiri and Pourboghrat, 2010; Watanabe et al., 2010; Sung et al., 2010), similar efforts have been much scarcer for HCP metals (Staroselsky, 1998; Staroselsky and Anand, 2003; Graff et al., 2007; Mayeur and McDowell, 2007; Tang et al., 2009; Mayama et al., 2009; Prakash et al., 2009; Choi et al., 2010b; Choi et al., 2010a; Lévesque et al., 2010). Despite the relatively ancient interests in HCP metals, the intrinsic mechanisms of HCP crystalline deformation, such as twinning (generally more present than in fcc and bcc metals), twin-slip interaction, or twin polarization among others, are still, as of now, not fully understood (Jérusalem 
et al., 2008; Wang et al., 2009a; Yue et al., 2010; Shen et al., 2010). Among these efforts, Staroselsky and Anand (Staroselsky, 1998; Staroselsky and Anand, 2003) developed a non-hardening rate-independent model of Magnesium alloy AZ31 aimed at reproducing the experimental behavior of tension and compression tests. Graff et al. presented a crystallographic model of Mg but without taking into account the reorientation of the twinned volume (Graff et al., 2007). Mayeur and McDowell developed a HCP model for Ti-6Al-4V alloy, in which twinning is less likely to occur (Mayeur and McDowell, 2007). Tang et al. proposed a crystal plasticity model aimed at simulating cup drawing of Mg alloy AZ31 (Tang et al., 2009) and Mayama et al. studied the effect of twinning deformation and rotation in a crystal plasticity model on pure Mg deformation (Mayama et al., 2009). Prakash et al. modeled the evolution of texture of AZ31 alloy but without differentiating between the different cross-hardening mechanisms (Prakash et al., 2009). Choi and coworkers recently proposed a similar model focusing their analysis on stress concentration and texture evolution of AZ31 at high temperature studies in which case the sequence of mechanisms of deformation is intrinsically different (Choi et al., 2010b; Choi et al., 2010a). Lévesque et al. developed a model for AM30 alloy at high temperature but without taking into account slip-twin interaction (Lévesque et al., 2010). Finally, Izadbakhsh et al. proposed a complex model a priori involving primary, secondary and tertiary slip systems with primary and secondary contraction/extension twin systems (Izadbakhsh et al., 2011). Because of the significant amount of accounted mechanisms, this approach however involves a daunting number of parameters difficultly identifiable experimentally, and leading to non-uniqueness of the solutions.

In this work, we propose to complement the model of Staroselsky and Anand by adding differentiated self- and crosshardening between slip and twin systems taking a special attention to the individual calibration of each one of the interaction parameters. All the parameters of this model are taken out of the literature when available, and modified as a function of their individual physical effect on the deformation of the material. The model is then calibrated and validated against uniaxial compression tests done for a texture sample of Mg alloy AZ31 along both RD and ND. The evolution of texture, the slip/ twin activity, and the stress-strain curves are analyzed and matched against experimental results for all experiments with one unique set of parameters. The model is ultimately used to cast light on the controversy exposed above and a failure criterion based on slip activity is proposed. Finally, the overall model as well as the failure criterion are validated against experimental results of a plane strain compression along RD, constraining along the Transverse Direction (TD).

In Section 2, we present the experimental campaign used as a reference for the computational model. The constitutive framework is then presented in Section 3, along with its calibration. The results, as well as the use of the model for the analysis of the controversy, failure mechanisms, and validation are exposed and discussed in Section 4 . The conclusion is finally given in Section 5.

\section{Experimental campaign}

The starting material is a sheet of the AZ31-O Mg alloy, with a thickness of $3 \mathrm{~mm}$ and a grain size of approximately $13 \mu \mathrm{m}$. The composition of this material is summarized in Table 1.

Uniaxial compression tests were carried out at room temperature and at $10^{-4} \mathrm{~s}^{-1}$ along RD in an electromechanical Servosis ME 405/10 testing machine located at the National Center for Metals Research (CENIM, Madrid, Spain). The specimens were $3 \mathrm{~mm} \times 3 \mathrm{~mm} \times 4.5 \mathrm{~mm}$ prisms. With the aim of analyzing the evolution of texture during compression, tests were interrupted at several intermediate strains: $2.5 \%, 5 \%, 7 \%, 11 \%$, and $14 \%$. Additional compression tests were carried out along ND under the same conditions of temperature and strain rate in $3 \mathrm{~mm} \times 3 \mathrm{~mm} \times 3 \mathrm{~mm}$ specimens. A note should be made that compression along RD is equivalent to a compression perpendicular to the c-axis while compression along ND is equivalent to a compression parallel to the c-axis. For both compression cases (RD and ND), three tests were carried out exhibiting a reasonable reproducibility, and the two experimental stress-strain curves used for calibration (see Fig. 3) correspond in both conditions to the average of the three associated tests. The textures present in both the as-received and deformed AZ31 samples were measured by the Schulz reflection method in a Philips Xpert-Pro Panalytical X-ray diffractometer furnished with a PW3050/60 goniometer, located at the CAI X-ray Diffraction of the University Complutense in Madrid, Spain. The radiation used was $\beta$-filtered $\mathrm{Cu} \mathrm{K} \alpha$. The surface area examined was about $2 \mathrm{~mm}^{2}$. The polar angle ranged from $0^{\circ}$ to $75^{\circ}$ in steps of $3^{\circ}$. Irradiation time at each step was $2 \mathrm{~s}$. The measured incomplete (1010), (0002), (1011), (1012), (112̄0) and (1013) pole figures were corrected for background and defocusing using the Philips XPert software. The MTEX Matlab open source software (Bachmann et al., 2010) was then utilized to calculate the orientation distribution function (ODF) from the corrected pole figures and, from the ODF, the final complete pole figures. Sample preparation for texture measurement included grinding with increasingly finer SiC papers, whose grit size ranged from 320 to 2000.

Table 1

Composition of the AZ31 alloy under study (in wt. \%).

\begin{tabular}{lllll}
\hline $\mathrm{Al}$ & $\mathrm{Zn}$ & $\mathrm{Mn}$ & $\mathrm{Ca}$ & $\mathrm{Si}$ \\
\hline $2.5-3.5$ & $0.7-1.3$ & $0.20 \mathrm{~min}$ & 0.04 max & $0.30 \mathrm{max}$ \\
$\mathrm{Cu}$ & $\mathrm{Ni}$ & $\mathrm{Fe}$ & Others & $\mathrm{Mg}$ \\
\hline 0.05 max & 0.005 max & 0.005 max & 0.030 max & Remaining \\
\hline
\end{tabular}




\section{Numerical setup}

In this section, we introduce the constitutive framework, followed by a description of the finite element model, setup and calibration.

\subsection{Constitutive framework}

The constitutive framework proposed in this work is based on a single-crystal plasticity framework modified to account for twinning reorientation. It closely follows the work of Staroselsky and Anand (Staroselsky, 1998; Staroselsky and Anand, 2003). For completeness, we provide a summary of its formulation and highlight the novelties of this new model.

\subsubsection{Crystal plasticity continuum formulation}

The total deformation of a crystal is the result of three main mechanisms: dislocation motion within the active slip systems, twinning motion within the active twin systems and lattice distortion. Following Lee (Lee, 1969), the deformation gradient tensor $\mathbf{F}$ can be uniquely decomposed following:

$$
\mathbf{F}=\mathbf{F}^{e} \cdot \mathbf{F}^{p}
$$

where $\mathbf{F}^{p}$ and $\mathbf{F}^{e}$ are respectively the deformation gradient tensor accounting for the cumulative effect of dislocation motion and shear due to twinning, and the elastic distortion of the crystal lattice, with $\operatorname{det}\left(\mathbf{F}^{e}\right)>0$ and $\operatorname{det}\left(\mathbf{F}^{p}\right)=1$. This $\operatorname{distortion}$ gives rise to the Cauchy stress $\sigma$.

The deformation power per unit reference volume is thus defined by

$$
\mathcal{P}=\mathbf{P}: \dot{\mathbf{F}}=\mathbf{S}^{e}: \dot{\mathbf{E}}^{e}+\left(\mathbf{C}^{e} \cdot \mathbf{S}^{e}\right): \mathbf{L}^{p}
$$

where

$$
\begin{aligned}
& \mathbf{P}=\operatorname{det}(\mathbf{F}) \boldsymbol{\sigma} \cdot \mathbf{F}^{-T} \\
& \mathbf{S}^{e}=\operatorname{det}\left(\mathbf{F}^{e}\right) \mathbf{F}^{e-1} \cdot \boldsymbol{\sigma} \cdot \mathbf{F}^{e-T} \\
& \mathbf{C}^{e}=\mathbf{F}^{e T} \cdot \mathbf{F}^{e} \\
& \mathbf{E}^{e}=\frac{1}{2}\left(\mathbf{C}^{e}-\mathbf{I}\right) \\
& \mathbf{L}^{p}=\dot{\mathbf{F}}^{p} \cdot \mathbf{F}^{p-1}
\end{aligned}
$$

are respectively the first Piola-Kirchhoff stress tensor, the second Piola-Kirchhoff stress tensor relative to the relaxed configuration, the right Cauchy-Green elastic deformation tensor, the Green-Lagrange elastic strain and the plastic velocity gradient tensor.

Assuming a linear elastic relation, as it is usually done in metallic single crystals, the constitutive equation is given by Staroselsky and Anand (2003):

$$
\mathbf{S}^{e}=\mathcal{C}: \mathbf{E}^{e}
$$

where $\mathcal{C}$ is a fourth-order anisotropic elasticity tensor.

By projecting $\mathbf{S}^{e}$ on the slip system $i$ and twin system $\alpha$, the resolved shear stress in systems $i$ and $\alpha$ are then given by:

$$
\left\{\begin{array}{l}
\tau^{i}=\left(\mathbf{C}^{e} \cdot \mathbf{S}^{e}\right): \mathbf{S}_{0}^{i} \\
\tau^{\alpha}=\left(\mathbf{C}^{e} \cdot \mathbf{S}^{e}\right): \mathbf{S}_{0}^{\alpha}
\end{array}\right.
$$

where

$$
\left\{\begin{array}{l}
\mathbf{S}_{0}^{i}=\mathbf{m}_{0}^{i} \otimes \mathbf{n}_{0}^{i} \\
\mathbf{S}_{0}^{\alpha}=\mathbf{m}_{0}^{\alpha} \otimes \mathbf{n}_{0}^{\alpha}
\end{array}\right.
$$

are the Schmid tensors for slip system $i$ and twin system $\alpha$ in the reference configuration. In this equation, slip (resp. twin) system $i$ (resp. $\alpha$ ) is characterized by a unit normal $\mathbf{n}_{0}^{i}$ (resp. $\mathbf{n}_{0}^{\alpha}$ ) to the slip (resp. twin) plane, and a unit vector $\mathbf{m}_{0}^{i}$ (resp. $\mathbf{m}_{0}^{\alpha}$ ) denoting the slip (resp. twin) direction in the reference configuration.

Extending (Taylor, 1938) and (Rice, 1971) to include the twinning components, the kinematics of dislocation of motion and twin shear can be described by:

$$
\mathbf{L}^{p}=\sum_{i} \operatorname{sign}\left(\tau^{i}\right) \dot{\gamma}^{i} \mathbf{S}_{0}^{i}+\sum_{\alpha} \operatorname{sign}\left(\tau^{\alpha}\right) \dot{\gamma}^{\alpha} \mathbf{S}_{0}^{\alpha}
$$

where $\dot{\gamma}^{i}$ (resp. $\dot{\gamma}^{\alpha}$ ) is the shear rate on slip (resp. twin) system $i$ (resp. $\alpha$ ). Subsequently for simplification, the superscript $i$ (and $j$ ) will refer to a slip system, and $\alpha$ (and $\beta$ ) to a twin system. 
Introducing $s_{i / \alpha}$ as the CRSS in system $i / \alpha$, the conditions for slip and twinning, as well as the associated flow rule, are written as:

$$
\left\{\begin{array}{l}
\phi^{i}=\left|\tau^{i}\right|-s^{i} \leqslant 0 \\
\phi^{\alpha}=\tau^{\alpha}-s^{\alpha} \leqslant 0 \\
\dot{\gamma}^{i / \alpha} \geqslant 0, \quad \text { and } \dot{\gamma}^{i / \alpha} \phi^{i / \alpha}=0
\end{array}\right.
$$

Note that the unidirectionality of tensile twinning $\{10 \overline{1} 2\}\langle\overline{1} 011\rangle$ is accounted for by relaxing the absolute value condition on the resolved shear stress $\tau^{\alpha}$.

In Staroselsky and Anand (2003), the flow rule was modified to include grain boundary deformation mechanisms within a "grain boundary layer" surrounding each grain. This feature was accounted for by adding an isotropic plasticity flow rule component to Eq. (7) weighted by a given grain boundary proportion. However, for the grain size observed in our experimental samples $(\sim 13 \mu \mathrm{m})$, it has been shown that grain boundary deformation mechanisms are not significant at room temperature (Valle and Ruano, 2009). As a consequence, this term was not included in the model presented here.

Finally, the evolution equations for slip and twin CRSS are given by a generalized linear hardening relation between the CRSS and the shear rates of all systems:

$$
\left\{\begin{array}{l}
\dot{s}^{i}=\sum_{j} h^{i j} \dot{\gamma}^{j}+\sum_{\beta} h^{i \beta} \dot{\gamma}^{\beta} \\
\dot{s}^{\alpha}=\sum_{\beta} h^{\alpha \beta} \dot{\gamma}^{\beta}+\sum_{j} h^{\alpha j} \dot{\gamma}^{j}
\end{array}\right.
$$

In this expression, $h^{i j}, h^{i \beta}, h^{\alpha \beta}$ and $h^{\alpha j}$ are the hardening moduli accounting respectively for the slip-slip, twin-slip, twin-twin and slip-twin interactions. In Staroselsky and Anand (2003), the moduli were taken equal to zero under the assumption that the hardening mechanisms were exclusively due to grain boundary mechanisms. Here, the moduli are chosen to follow power law type relations:

$$
\left\{\begin{array}{l}
h^{i j}=q^{i j} h^{j}, \text { with }\left\{\begin{array}{l}
q^{i j}=\left(q_{s l}+\left(1-q_{s l}\right) \delta^{i j}\right) \\
h^{j}=h_{0 ; s l}\left(1-\frac{s^{j}}{\widetilde{s}_{s l}}\right)^{a_{s l}}
\end{array}\right. \\
h^{\alpha \beta}=q^{\alpha \beta} h^{\beta}, \text { with }\left\{\begin{array}{l}
q^{\alpha \beta}=\left(q_{t w}+\left(1-q_{t w}\right) \delta^{\alpha \beta}\right) \\
h^{\beta}=h_{0 ; t w}\left(1-\frac{s^{\beta}}{\tilde{s}_{t w}}\right)^{a_{t w}}
\end{array}\right. \\
h^{i \beta}=h_{0 ; t w-s l}\left(1-\frac{s^{\beta}}{\tilde{s}_{t w-s l}}\right)^{a_{t w-s l}} \\
h^{\alpha j}=h_{0 ; s l-t w}\left(1-\frac{s^{j}}{\tilde{s}_{s l-t w}}\right)^{a_{s l-t w}}
\end{array}\right.
$$

where $\delta_{i j}$ is the Kronecker symbol, where the quadruplets $\left(h_{0 ; s l}, h_{0 ; t w}, h_{0 ; t w-s l}, h_{0 ; s l-t w}\right),\left(\tilde{s}_{s l}, \tilde{s}_{t w}, \tilde{s}_{t w-s l}, \tilde{s}_{s l-t w}\right)$ and $\left(a_{s l}, a_{t w}\right.$, $\left.a_{t w-s l}, a_{s l-t w}\right)$ are respectively the reference self-hardening parameters, the saturation stresses and the hardening exponents for (slip-slip, twin-twin, slip-twin, twin-slip) interactions, and where $\left(q_{s l}, q_{t w}\right)$ are the ratios of reference cross-hardening parameter to reference self-hardening parameter for (slip, twin). Simple power-law relations such as the ones proposed here in Eq. (14) are commonly used in crystal plasticity continuum models (Anand and Kothari, 1996; Staroselsky, 1998; Anand, 2004; Roters et al., 2010; Lee et al., 2010; Zamiri and Pourboghrat, 2010; Choi et al., 2010a,). Note that other formulations using Voce-type law or more generally hyperbolic functions could also be used; but all generally present the same drawback of being exclusively dependent on the CRSS, occulting any dependence on the lattice defect population for example (Roters et al., 2010). However, in the interest of limiting the number of parameters introduced in the current model, the choice was made to use a simple power-law, while acknowledging the fact that other models more physically grounded could potentially be used (Kadiri and Oppedal, 2010). Future studies will aim at studying the effect of the choice of the hardening model on the crystal deformation.

In the following, the CRSS will be defined by $s_{0 ; s l}$ and $s_{0 ; t w}$ for the slip and twin systems respectively. Finally, note that the slip parameters are a priori different for basal, pyramidal $\langle c+a\rangle$, pyramidal $\langle a\rangle$ and prismatic slips, in which case the subscript "0;sl" for all the above parameters will be replaced by "0;basal", "0;pyr $\langle c+a\rangle$ ", "0;pyr $\langle a\rangle$ " and "0;prism" respectively, when differentiated values are chosen.

\subsubsection{Crystal rotation}

A total Lagrangian scheme is used for texture updating, see Staroselsky (1998) for more details. Note that such scheme can predict accurately the final texture but that intermediate textures might not be predicted with the same precision.

By definition, shear by twinning is accompanied by a local rotation of the crystal. This transformation, defined for HCP metals by the rotation matrix (Staroselsky, 1998)

$$
\mathbf{R}^{\alpha}=2 \mathbf{n}^{\alpha} \otimes \mathbf{n}^{\alpha}-\mathbf{I}
$$


where $\mathbf{n}^{\alpha}$ is the current twin plane normal of the twin system $\alpha$, rotates the crystal such that the final orientation mirrors the initial one with respect to the twin plane. Such change is of significant importance as a given crystal, once rotated by nearly $90^{\circ}$ as a consequence of twinning, might have a unfavorable orientation for further twinning, thus switching the main crystal deformation mechanisms from twin driven to slip driven mechanisms.

We follow here the model proposed by Van Houtte (Van Houtte, 1978). The twin volume fraction $f^{\alpha}$ evolution in twin system $\alpha$ is characterized by

$$
\left\{\begin{array}{l}
f^{\alpha}=\int_{0}^{t} \dot{f}^{\alpha} d t \\
\dot{f}^{\alpha}=\frac{\dot{\gamma}^{\alpha}}{\gamma_{0}}
\end{array}\right.
$$

where $\gamma_{0}$ is the twinning shear. A random number $\zeta \in\left[\zeta_{\min }, \zeta_{\max }\right]$, where $\zeta_{\min }$ and $\zeta_{\max }$ represent the lower and higher bound for twinning event, is picked at a given time $t$, and, within the chosen representative volume element (RVE) of an individual crystal, $f_{\max }=\max _{\alpha}\left(f^{\alpha}\right)$ is compared to $\zeta$. If $f_{\max }>\zeta$, the RVE is assumed fully rotated, the crystal lattice (i.e. all current slip and twin systems normals $n^{i / \alpha}$ and directions $m^{i / \alpha}$ ) is rotated following Eq. (15), and the volume fractions $f^{\alpha}$ are reinitialized to zero.

\subsection{Finite element model}

The constitutive model described above was used in the finite element program ABAQUS/Explicit (Dassault Systèmes, 2010) by implementing the previous constitutive law in a "user material" subroutine. In this subsection, we present first the finite element discretization of the polycrystal model, followed by the model calibration.

\subsubsection{Finite element discretization}

In this work, we follow the example of Staroselsky and Anand (2003) and idealize the polycrystalline sample as a stacked structure of $12 \times 12 \times 18=2592$ linear cubic elements with reduced integration and hourglass control. Each element represents a full crystal and is assigned its own crystal lattice orientation. Such approach can present serious limitations when used for studying microstructural evolution within a grain, where multiple elements are needed. However its flexibility constitutes a significant computational advantage for simulation models aimed at studying the overall behavior of a full polycrystalline samples, such as in this work. The mesh is shown in Fig. 1.

The experimental uniaxial compression tests (Section 2) were simulated by imposing Dirichlet boundary conditions on the top and bottom surfaces of the model. Both of them were constrained laterally to account for the absence of gliding during contact in the experimental setup, the top surface was displaced at a given velocity along the vertical direction while the bottom one was constrained. The model being rate-independent, the actual compression velocity and the density were

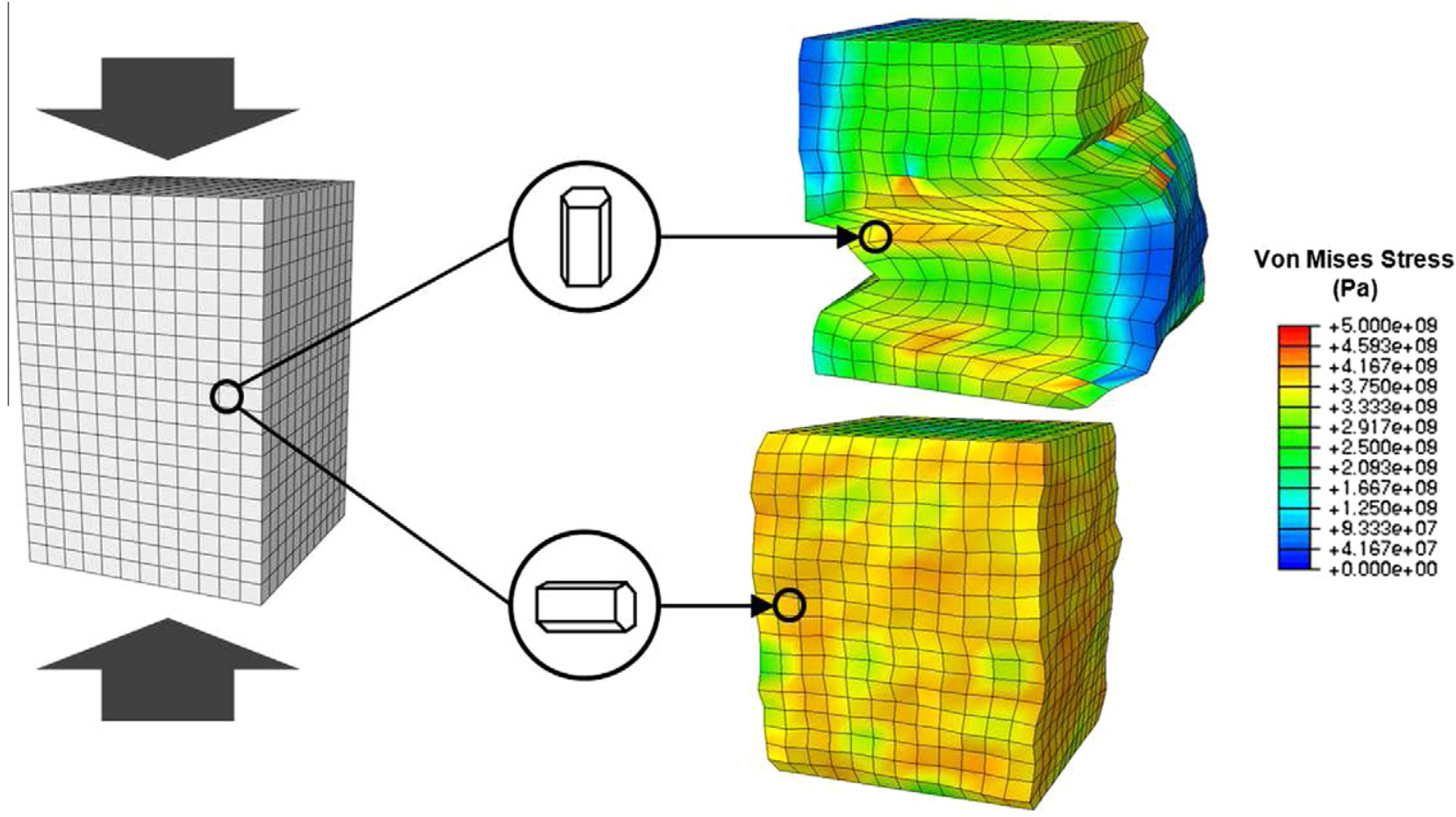

Fig. 1. Uniaxial compression numerical tests for two cases: along ND and RD. The resulting Von Mises stress field is plotted for both cases. 
chosen so as to minimize inertial effects and computational calculation time. The resulting simulation is thus fully quasistatic, which is a good approximation of the very low rate of the experimental compression $\left(10^{-4} \mathrm{~s}^{-1}\right)$.

Note finally that for all the simulations presented in this work, both spatial and temporal convergences were verified.

\subsubsection{Model calibration}

3.2.2.1. Compression/double twinning. The significance of compression and double twinning in accommodating c-axis compression in magnesium alloys is still not clear. Some studies have recently reported the occurrence of compression and double twinning in polycrystalline $\mathrm{Mg}$ alloys during c-axis compression (Nave and Barnett, 2004; Barnett et al., 2004b; Keshavarz and Barnett, 2006; Cizek and Barnett, 2008; Al-Samman and Gottstein, 2008). However, traces of these types of twins are only observed in very small regions, often very close to the fracture surfaces. It has nevertheless been recently reported that, despite the low volume fraction of such twins, their effect in the hardening of the AZ31 alloy might be important (Knezevic et al., 2010).

On the other hand, it is also widely accepted that pyramidal slip accommodates most of the compression strain along the c-axis (Agnew et al., 2003; Knezevic et al., 2010).

In view of the controversial role of compression/double twinning, we have chosen not to include this deformation mechanisms in our continuum model, as a first approximation.

3.2.2.2. Texture. The model was calibrated against both experimental setups described in Section 2. In the first case, the c-axis of the overall texture is on average aligned with the compression direction, whereas, in the second case, it is perpendicular to it. It must be emphasized that the material sample being the same, one sample texture in one case simply consists in a rotation of $90^{\circ}$ of a sample of the other case. Accordingly, the two uniaxial compression simulation will also be done for the same material (i.e. same material parameters), but with the texture of one mesh being a rotation of $90^{\circ}$ of the other one (see Fig. 1). For the sake of rigor, the reader must keep in mind that the random individual orientations of each grain are only parallel or perpendicular to this direction within a given random "noise".

The initial texture of the numerical model was chosen by giving to each one of the crystals the chosen preferential orientation for the c-axis, a fully random rotation around the c-axis, and a gaussian noise for each one of the resulting set of Euler angles. The pole figures for two given samples (RD and ND) were chosen for calibration and the gaussian noise for the three Euler angles was adjusted until a reasonable fit between experimental numerical textures was observed (see Fig. 2).
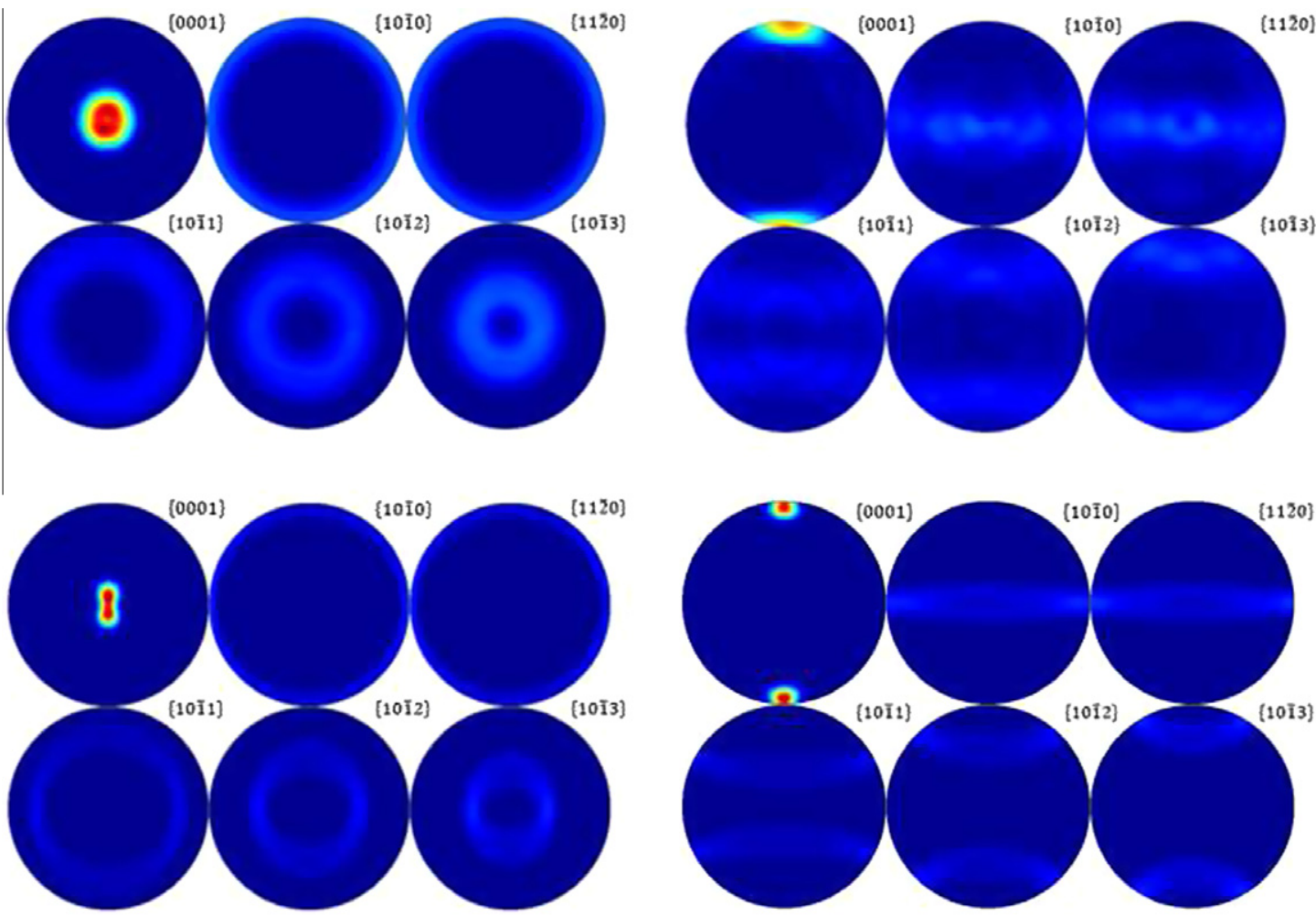

(a) along ND

(b) along RD

Fig. 2. Comparison between experimental (top) and numerical (bottom) initial texture for the two cases: (a) along ND; (b) along RD. 


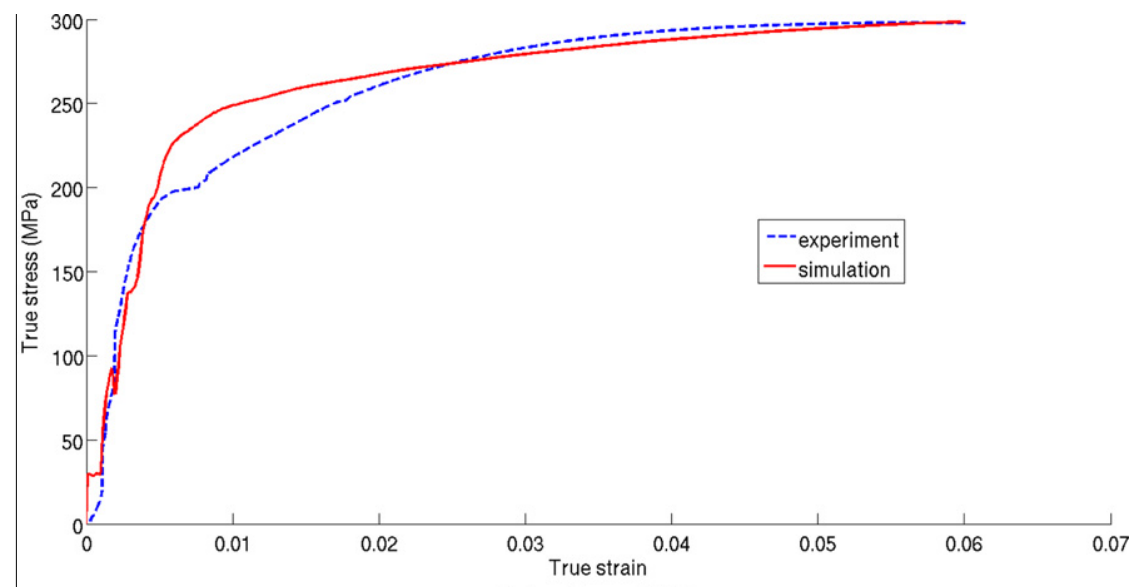

(a) along ND

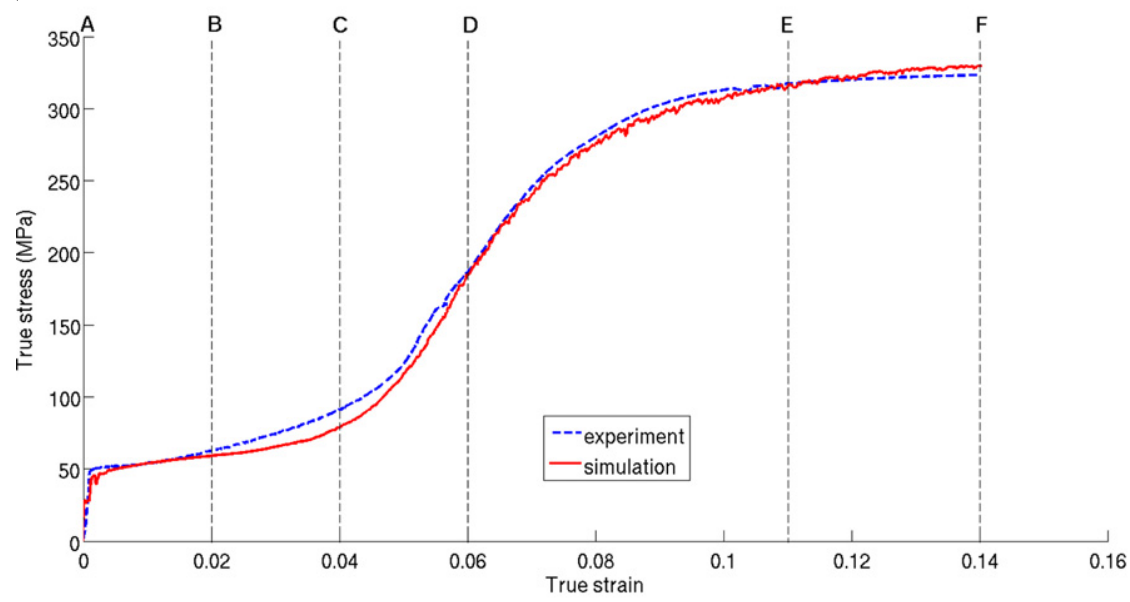

(b) along RD

Fig. 3. Stress-strain curve (true) of uniaxial compression after calibration for the two cases: (a) along ND; (b) along RD.

Note that both of the experimental pole figures seem to be more "diffuse" around their two poles than the numerical ones. However, the numerically modeled texture used in this work is chosen to be representative of all samples in general. This explains the observed differences between the pole figure for one given experimental sample and the one for the numerical model, representative of all samples. Finally, the observed "splitting" in Fig. 2, typical of rolling textures in Mg alloys, has been attributed to the operation of pyramidal slip during plane strain deformation (Agnew et al., 2001).

3.2.2.3. Material parameters. The material parameters were chosen according to the following scheme. Initial parameters were taken out of the literature (Staroselsky, 1998; Staroselsky and Anand, 2003; Jain and Agnew, 2007; Graff, 2007; Watanabe and Ishikawa, 2009; Choi et al., 2010a). The ones that differed within these references were chosen so as to achieve the closest fit with the experimental stress-strain curves. Finally, the other parameters (namely the slip-twin/ twin-slip interactions and twinning rotation parameters) were calibrated so as to achieve the best fit keeping the previous parameters fixed. The final set of parameters are given in Table 3 and the resulting stress-strain curves of the uniaxial compressions for the two cases are shown in Fig. 3.

For the purpose of analysis, the stress-strain curve for the compression along RD has been divided into six regions. The deformation states at which one region transitions to another one are marked by A, B, C, D, E and F, see Fig. 3(b) and Table 2.

Note that the hardening related to the effect of slips on tensile twinning was suppressed based on the relatively scarce information in the literature on this interaction, and the observation that the region between the states of deformation A and C (see Fig. 3(b)) ${ }^{1}$ is only weakly dependent on this parameter even for large values of $h_{0 ; s l-t w}$. Additionally, increasing this parameter would only steepen the numerical curve away from the experimental one. The $\left(\zeta_{\min }, \zeta_{\max }\right)$ parameters played an important role in the C-to-D portion of the curve and the twin-slip hardening parameters in the C-to-E portion.

\footnotetext{
${ }^{1}$ This region should actually a priori be the one most directly influenced by these parameters (influence of already existing basal slip on nascent twinning).
} 
Table 2

Transition strain between regions.

\begin{tabular}{llllll}
\hline $\mathrm{A}$ & $\mathrm{B}$ & $\mathrm{C}$ & $\mathrm{D}$ & $\mathrm{E}$ & $\mathrm{F}$ \\
\hline $0 \%$ & $2 \%$ & $4 \%$ & $6 \%$ & $11 \%$ & $14 \%$ \\
\hline
\end{tabular}

The final shape of both simulated samples after deformation with the corresponding Von Mises stress fields are shown in Fig. 1.

3.2.2.4. Material parameters sensibility. For a given set of parameters, it is known that a unique set of active slip systems will be found (Anand and Kothari, 1996). However, it is not clear whether a calibration based on both considered stress-strain curves should be enough to guarantee the unicity of the set of parameters. For example, one would want to know whether a set of pyramidal hardening parameters along with a set of twin hardening parameters could not be exchanged by two other sets without noticeable differences in the stress-strain curves. To this end, an extensive parameter sensibility study has been done in which each individual parameter is varied by $\pm 20 \%, \pm 50 \%$ or $\pm 100 \%$ depending on the sensibility of the parameter. The strain at which the first major noticeable influence of these variations on one of the portions of the RD/ND compression stress-strain curves was then marked down and reported in Table 4. Note that a non-marked cell does not mean that there is no influence of the parameter but that a much more important variability has been observed at a different strain (or on the other curve).

Table 3

Material parameters after calibration.

\begin{tabular}{|c|c|c|c|}
\hline $\mathbf{S}_{\mathbf{0} \text {;basal }}$ & $\mathbf{S}_{\mathbf{0} ; \mathbf{p y r}\langle c+a\rangle}$ & $\mathbf{S}_{\mathbf{0} ; \mathbf{p y r}\langle a\rangle}$ & $\mathbf{S}_{\mathbf{0} ; \text { prism }}$ \\
\hline $9 \mathrm{MPa}$ & $115 \mathrm{MPa}$ & $115 \mathrm{MPa}$ & $80 \mathrm{MPa}$ \\
\hline $\begin{array}{l}\mathbf{h}_{\mathbf{0} ; s l} \\
600 \mathrm{MPa}\end{array}$ & $\begin{array}{l}\mathbf{h}_{\mathbf{0} ; t w} \\
80 \mathrm{MPa}\end{array}$ & $\begin{array}{l}\mathbf{h}_{\mathbf{0} ; s l-t w} \\
0 \mathrm{MPa}\end{array}$ & $\begin{array}{l}\mathbf{h}_{\mathbf{0} ; t w-s l} \\
1200 \mathrm{MPa}\end{array}$ \\
\hline $\begin{array}{l}\tilde{\mathbf{s}}_{\text {basal }} \\
15 \mathrm{MPa}\end{array}$ & $\begin{array}{l}\tilde{\mathbf{s}}_{\mathbf{p y r} \mathbf{r}+\mathbf{c}\rangle} \\
190 \mathrm{MPa}\end{array}$ & $\begin{array}{l}\tilde{\mathbf{s}}_{\mathbf{p y r} \mathbf{a}\rangle} \\
190 \mathrm{MPa}\end{array}$ & $\begin{array}{l}\tilde{\mathbf{s}}_{\text {prism }} \\
150 \mathrm{MPa}\end{array}$ \\
\hline $\begin{array}{l}\mathbf{S}_{\mathbf{0} ; t w} \\
17.5 \mathrm{MPa}\end{array}$ & $\begin{array}{l}\tilde{\mathbf{s}}_{\mathbf{t w}} \\
100 \mathrm{MPa}\end{array}$ & $\begin{array}{l}\tilde{\mathbf{s}}_{\mathbf{s l}-\mathbf{t w}} \\
\mathrm{n} / \mathrm{a}\end{array}$ & $\begin{array}{l}\tilde{\mathbf{s}}_{\mathbf{t w}-\mathbf{s l}} \\
100 \mathrm{MPa}\end{array}$ \\
\hline $\begin{array}{l}\mathbf{a}_{\mathbf{s 1}} \\
0.6\end{array}$ & $\begin{array}{l}a_{t w} \\
2\end{array}$ & $\begin{array}{l}\mathbf{a}_{\mathbf{s} 1-t w} \\
\mathrm{n} / \mathrm{a}\end{array}$ & $\begin{array}{l}\mathbf{a}_{\mathbf{t w}-s l} \\
2\end{array}$ \\
\hline $\begin{array}{l}\mathbf{q}_{\mathbf{s l}} \\
4\end{array}$ & $\mathbf{q}_{1}$ & $\begin{array}{l}\zeta_{\min } \\
0.75\end{array}$ & $\begin{array}{l}\zeta_{\max } \\
0.8\end{array}$ \\
\hline $\begin{array}{l}\gamma_{\mathbf{0}} \\
0.129\end{array}$ & $\begin{array}{l}\mathbf{C}_{\mathbf{1 1}} \\
58 \mathrm{GPa}\end{array}$ & $\begin{array}{l}\mathbf{C}_{\mathbf{1 2}} \\
25 \mathrm{GPa}\end{array}$ & $\begin{array}{l}\mathbf{C}_{\mathbf{1 3}} \\
20.8 \mathrm{GPa}\end{array}$ \\
\hline $\begin{array}{l}\mathbf{C}_{\mathbf{3 3}} \\
61.2 \mathrm{GPa}\end{array}$ & & $\begin{array}{l}\mathbf{C}_{\mathbf{5 5}} \\
16.6 \mathrm{GPa}\end{array}$ & \\
\hline
\end{tabular}

Table 4

Material parameters sensibility.

\begin{tabular}{|c|c|c|c|c|c|c|c|c|}
\hline Parameters & & $R D_{A}$ & $R D_{B}$ & $R D_{C}$ & $R D_{D}$ & $R D_{E}$ & $R D_{F}$ & $N D$ \\
\hline \multirow[t]{5}{*}{ Twin } & $s_{0 ; t w}$ & & $\times$ & $\times$ & & & & \\
\hline & $\tilde{s}_{t w}$ & & $\times$ & & & & & \\
\hline & $h_{0 ; t w}$ & & $\times$ & & & & & \\
\hline & $a_{t w}$ & & $\times$ & $\times$ & & & & \\
\hline & $q_{t w}$ & & & $\times$ & $\times$ & & & \\
\hline \multirow[t]{2}{*}{ Twin Rotation } & $\zeta_{\min }$ & & & $\times$ & $\times$ & & & \\
\hline & $\zeta_{\max }$ & & & & $\times$ & $\times$ & & \\
\hline \multirow[t]{3}{*}{ Twin-Slip } & $\tilde{s}_{t w-s l}$ & & & & $x$ & $\times$ & & \\
\hline & $h_{0 ; t w-s l}$ & & & & $\times$ & $\times$ & & \\
\hline & $a_{t w-s l}$ & & & & $\times$ & $x$ & & \\
\hline \multirow[t]{9}{*}{ Slip } & $s_{0 ; p y r}$ & & & & & $\times$ & $\times$ & $\times$ \\
\hline & $\tilde{s}_{p y r}$ & & & & $\times$ & & & $\times$ \\
\hline & $S_{0 ; \text { prism }}$ & $\times$ & & & & & & \\
\hline & $\tilde{s}_{\text {prism }}$ & & & & $\times$ & & & \\
\hline & $s_{0 ; \text { basal }}$ & & & & & & & $\times$ \\
\hline & $\tilde{s}_{\text {basal }}$ & & $\times$ & & & & & $\times$ \\
\hline & $h_{0 ; s l}$ & & & & & & & $\times$ \\
\hline & $a_{s l}$ & & & & & & & $\times$ \\
\hline & $q_{s l}$ & & & & & & & $\times$ \\
\hline
\end{tabular}


Table 4 shows that the twinning, twin-slip interaction and pyramidal slips parameters are successive quasi-independent mechanisms in the compression along RD. Basal and prismatic slips influences are on the other hand overlapping independently some of the zones of influence of the other mechanisms, but basal slip parameters do also influence majoritatively the ND compression. Overall, a proper fit of the stress-strain curves at states A, B, C, D, E and F as well as for the ND compression curve can be done with a quasi-independent calibration of twinning, pyramidal and prismatical parameters majoratively for the RD compression case, and pyramidal and basal for the ND case (with cross-calibration for pyramidal), in this order. Additionally, the three main mechanisms (twinning, basal and pyramidal slips) are shown to influence in a complementary manner the stress-strain curves.

\section{Results and discussion}

In the previous section, the model was calibrated against two uniaxial compression tests with one unique set of material parameters, validating the ability of the model to describe the AZ31 deformation mechanisms under both slip- and twindominated deformations. These deformation mechanisms are identified in the following by studying texture evolution, slip/twin activities and the related controversy on pyramidal $\langle c+a\rangle$ splitting. Ultimately, a failure criterion based on slip activity and a final validation are proposed.

\subsection{Texture evolution and slip/twin activities}

The $\{0001\}$ pole figures at the experimental and simulated deformations states $\mathrm{A}, \mathrm{B}, \mathrm{C}, \mathrm{D}, \mathrm{E}$ and $\mathrm{F}$ for the compression along RD are illustrated in Fig. 4. Fig. 5 shows the normalized slip/twin activity versus the overall strain for both uniaxial compression cases.

The first clear conclusion is that in both cases, basal slip is the overall most important mechanism. After the initial yielding, the A-to-B region is mostly driven by twinning despite some basal slip activity. This basal activity is due to the systems that are slightly tilted and thanks to the very low basal CRSS. The initial presence of twinning is confirmed by the clear appearance of twin driven lattice rotation, as can be seen in the experimental $\{0001\}$ pole figure at state B (Fig. 4), followed by the sudden drop of its activity (Fig. 5(b)).

At state $\mathrm{C}$, the experimental pole figure shows that all the crystals have rotated. It appears that the simulated results are delayed in this rotation, rotating slowly until slightly after state $\mathrm{D}$. This delay in the pole figures can be explained by two factors:

A

\section{Experimental Numerical}
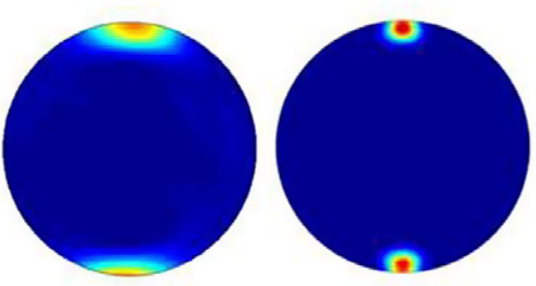

B
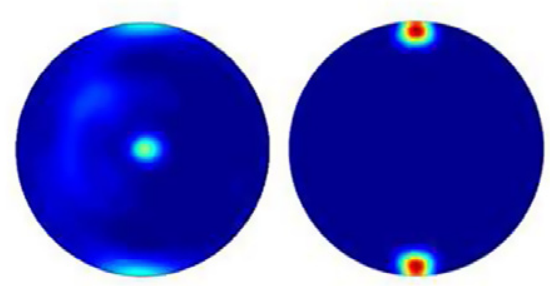

C
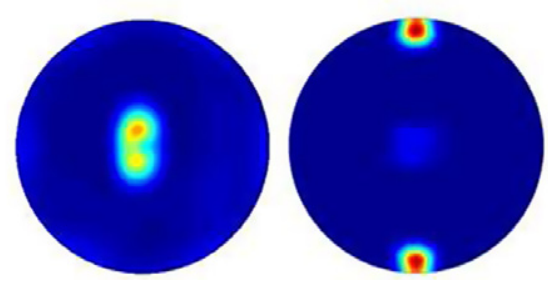

\section{Experimental}

D
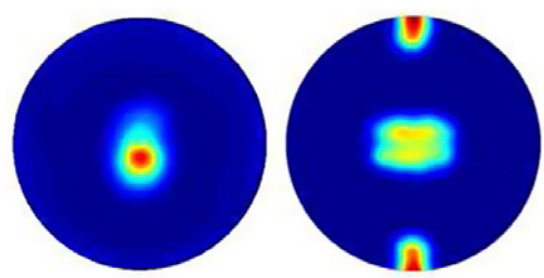

E
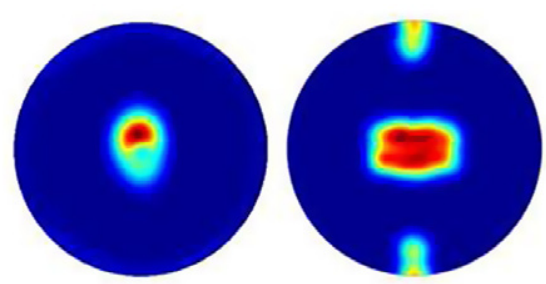

$\mathbf{F}$
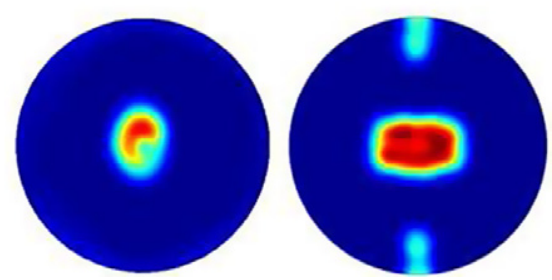

Fig. 4. Comparison between $\{0001\}$ experimental and numerical textures at deformation state A, B, C, D, E and F for the compression along RD. 


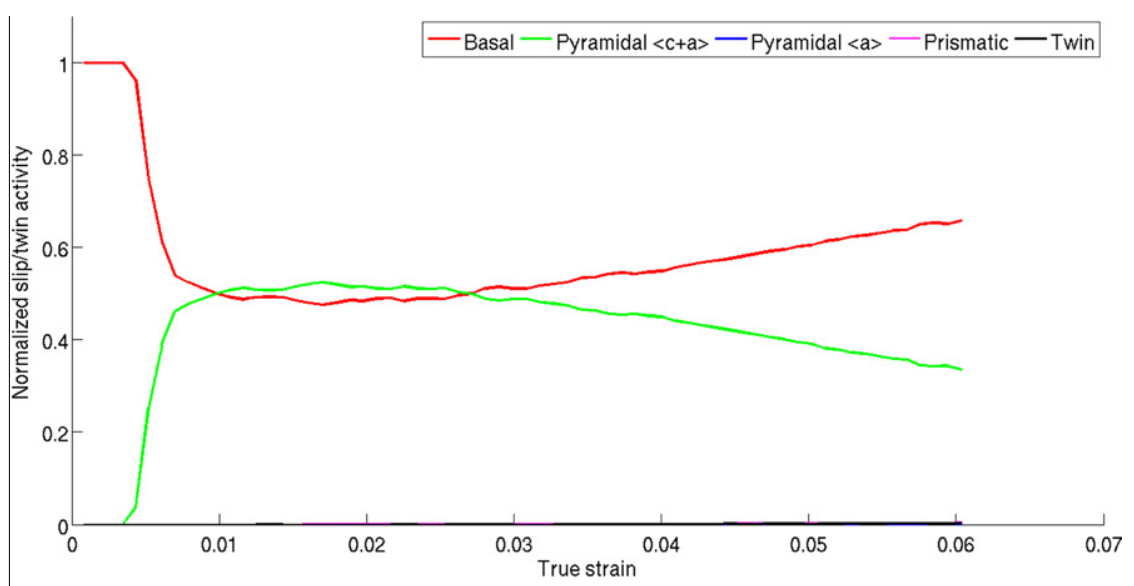

(a) along ND

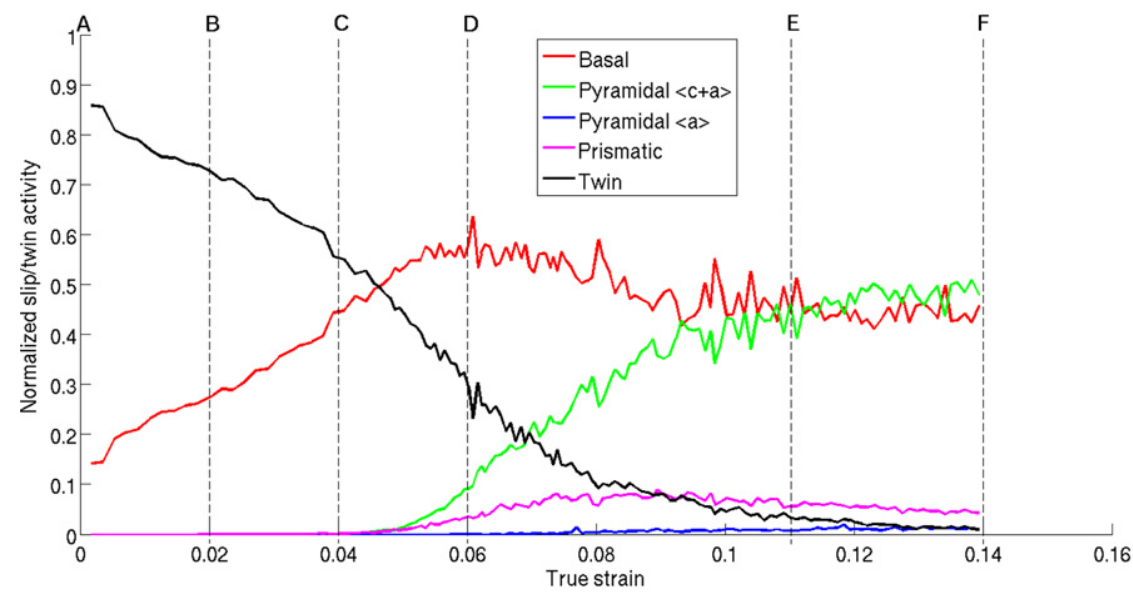

(b) along $\mathrm{RD}$

Fig. 5. Normalized slip/twin activity for both cases: (a) compression along the ND direction, (b) compression along the RD compression.

- Firstly, it has been experimentally observed that the boundaries of tensile twins migrate very rapidly (Knezevic et al., 2010). However, the model, because of its one-to-one association between grain and element, precludes a "gradual rotation" by twin growth within the grains, making it a sudden switch from one crystalline orientation to another one (see Section 3.1.2). This is actually confirmed by comparing the twinning rotation evolution for the simulation and the experiments, see Fig. 6. In this figure, the experimental volume fractions of twinned regions in the samples compressed uniaxially along RD were calculated at various strain levels from the X-ray Orientation Distribution Function (ODF) data using the software MTEX. A misorientation of $\pm 30^{\circ}$ was used (this value was identified by means of the orientation spread in the $\mathrm{ODF})^{2}$ As can be seen, the inflections of the curves are very similar, but there is a delay of roughly $4.5 \%$. One more time, this delay is explained by the binary-type rotation of the model, as opposed to gradual. In other words, the simulation curve on Fig. 6 is representative of the averaged fraction of fully rotated grains, and not of the averaged fraction of rotated lattice within each grain. This restriction of the model will be solved in future works by considering multiple elements per grain.

- Secondly, whereas the experimental pole figures are taken by considering a thin slice of material within the bulk, the simulated ones include the whole polycrystal, and, as can be seen on Fig. 7, the non-sliding boundary conditions are responsible for a twin rotation gradient close to the top and bottom surfaces. This restriction thus leads to an observed delay in the twin rotation when averaged over the whole sample. As an example, at $4 \%$ deformation, $13 \%$ of all the grains are rotated, but the outer and center element layers respectively have $1 \%$ and up to $27 \%$ of rotated grains, see Fig. 8 .

\footnotetext{
${ }^{2}$ Note that the twinned volume fraction was alternatively calculated in the sample deformed up to $4 \%$ by EBSD, showing similar results, however the technique described above being more flexible and time-efficient for post-processing, it was ultimately chosen for this study.
} 


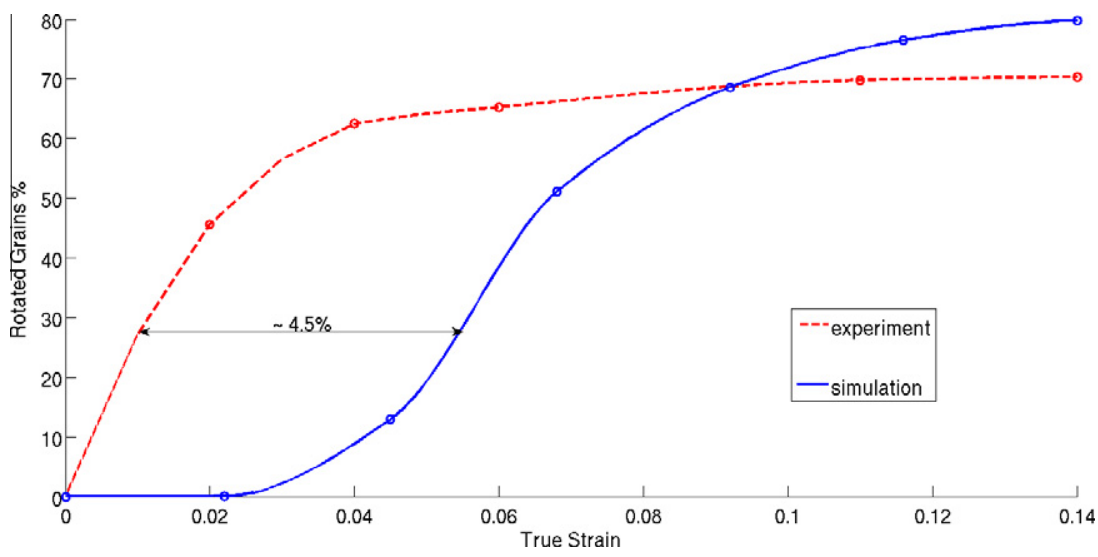

Fig. 6. Experimental and numerical twinning rotation fraction evolution.

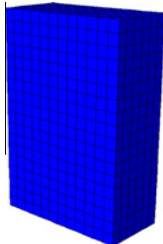

(a)

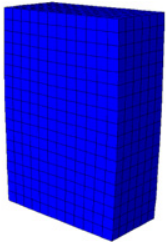

(b)

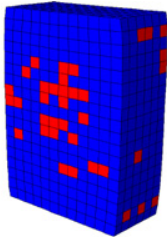

(c)

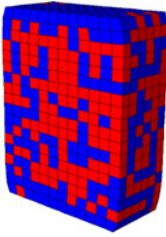

(d)

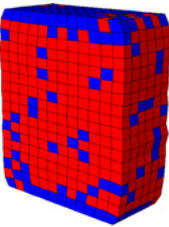

(e)

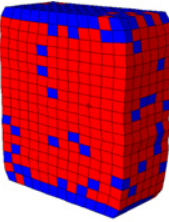

(f)

Fig. 7. Twinning rotation state in a longitudinal cut of the sample (blue: non-rotated, red: rotated) for the states of deformation (a), (b), (c), (d), (e) and (f). (For interpretation of the references to colour in this figure legend, the reader is referred to the web version of this article.)

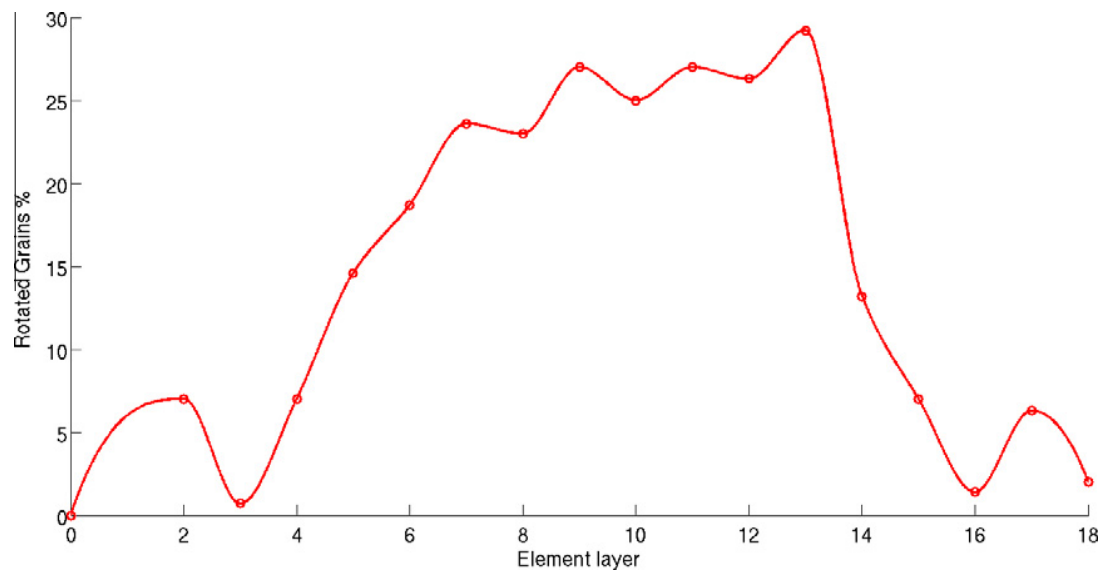

Fig. 8. Twinning rotation fraction as a function of the vertical element layer in the sample at $4 \%$ deformation.

During the rotation from $\mathrm{C}$ to $\mathrm{D}$, basal slip activity is slightly increasing before regaining its previous level after full rotation. Prismatic and pyramidal $\langle a\rangle$ activities are also increasing during this change of crystal orientation, but overall remain relatively small.

Finally, the D-to-E region, followed by the E-to-F one where all the main deformation mechanisms saturate, clearly exhibits a transition to pyramidal $\langle c+a\rangle$ slip dominated deformation (Fig. 5(b)). Such change is explained by the polarity of twinning, thus prohibiting its activity during compression when the c-axis is aligned with the compression direction. As a consequence, the next most favorable deformation mechanism is pyramidal $\langle c+a\rangle$ slip (with basal slip present during the whole deformation). This is confirmed in Fig. 5(a) where the crystals have the c-axis aligned with the compression axis from the beginning. In this case, basal slip is dominant at the beginning of the deformation, and when blocked by the misorientation of the neighboring grains, is transitioned to pyramidal $\langle c+a\rangle$ slip driven deformation. Note finally that all systems did 
not rotate at stages $\mathrm{E}$ and $\mathrm{F}$ as it did experimentally. This delay can be explained by the same factors that delayed the onset of rotation.

The analysis above shows that, despite its high room temperature CRSS, $\langle c+a\rangle$ pyramidal slips operate, in conjunction with basal slips, during room temperature compression of the AZ31 rolled sheet along RD and ND (Fig. 4). The activation of these two slip systems explains the texture development as well as the corresponding stress-strain curves (Fig. 3). This is consistent with the findings of Yi et al. (Yi et al., 2006), who determined the relative slip/twin activities during deformation of an AZ31 extruded bar along a direction perpendicular to the extrusion axis by viscoplastic self-consistent modeling and found that $\langle c+a\rangle$ slip does play an important role under such conditions. In their case, however, the contribution of $\langle c+a\rangle$ slip is smaller with respect to that of basal slip due to the wider spread of basal planes around the compression axis in their extruded bar than in the rolled sheet investigated here. Wang et al. (Wang et al., 2010) also recently calculated the slip/twin activity during uniaxial deformation of a rolled AZ31 sheet using several VPSC models. Specifically, they fitted the different models to experimental tension and compression tests along RD and then used the same parameters to predict compression along ND. They concluded that the affine self-consistent VPSC model gives the best overall performance. When compressing along ND, in both the affine VPSC model and the one presented here, only basal and pyramidal slips operate. However, the cumulative activity of pyramidal slip, predicted by the affine VPSC model, is significantly smaller than that obtained in the present work. When compressing along $\mathrm{RD}$, both models predict the activation of tensile twinning and basal slip in the first stages of deformation, but the relative contribution of twinning is much smaller when using the affine model than in our prediction. In the last stages of deformation both models predict the activation of both basal and pyramidal slips. Again, the affine VPSC model predicts a larger contribution of basal slip. In summary, similar deformation modes are predicted to operate using both the affine VPSC model and the current crystal plasticity FEM model. However, in all cases, the VPSC model estimates a higher relative contribution of basal slip. Such differences highlight the necessity for further comparisons between different numerical models, where a priori acceptable simplifications might possibly lead to erroneous description of the deformation mechanisms. Finally, the activity of $\langle c+a\rangle$ slip during the last stages of deformation of a rolled AZ31 sheet compressed along RD at $200{ }^{\circ} \mathrm{C}$ has also been predicted by Choi et al. using a similar model to the one presented in this work. This finding is, however, not very surprising, as it is well known that the CRSS for pyramidal slip decreases rapidly with temperature and therefore its activity increases significantly at temperatures higher than approximately $180{ }^{\circ} \mathrm{C}$.

\subsection{Fracture mechanisms}

An analysis of the sample fracture surface suggested that the material failure is stemming from intragrain semiductile failure (this work not reproduced here is available in Fernández (2009)). This could a priori indicate the formation of a shear zone eventually leading to an intragrain failure. In order to confirm or infirm this hypothesis, we define a criterion based on the cumulated average slip activity for slip system $i$ at time $t$

$$
\Gamma^{i}=\int_{t_{0}}^{t}\left\langle\dot{\gamma}^{i}\right\rangle d t
$$

where $\left\langle\dot{\gamma}^{i}\right\rangle$ is the average slip rate at time $t$ over the full sample, and $t_{0}$ the time reference. Note that such criterion is purposefully macroscopically averaged at the sample level. Defining a criterion at the grain level (thus defining a failure initiation criterion, see for example Jérusalem et al. (2008)) in a model such as here, where grains are modeled by only one element, would actually miss the purpose of the proposed criterion (defining overall sample failure).

It has been shown that a dislocation interacting with a twin boundary during twin growth is not transferred through the twin boundary, but instead is decomposed into interfacial defects (Serra and Bacon, 1996). An intragrain failure criterion based on slip accumulation thus requires that only the slip activity since the time of the last twin lattice rotation (if any) should be taken into account. Note that such consideration does not concern the hardening model, based on the assumption that previous dislocations, even possibly dismantled into other stacking faults, still participate to the lattice hardening. However the bulk of the crystal itself does not contain residual dislocation after the passing of the twin boundary (Serra and Bacon, 1996), and its relation to intragrain failure should be reinitialized. The time at which the stress-strain curve (see Fig. 3(b)) regains a quasi-elastic behavior after the rotation of the crystals $\left(\epsilon\left(t_{0}\right)=6 \%\right)$ was chosen as the "reinitialization time" $t_{0}$ (in the ND case, as very little twinning occurs, $t_{0}=0$ ). Fig. 9 shows the evolution of $\Gamma^{i}$ versus time for all slip systems for both cases (including the reinitialization after twin rotation when needed) up till experimental fracture. As could be expected from Fig. 5, prismatic and pyramidal $\langle a\rangle$ slip activity seem highly uncorrelated with a potential slip related failure mechanism. On the other hand, the cumulated average basal and pyramidal $\langle c+a\rangle$ activity reach the same value of $\sim 0.04$ and $\sim 0.015$, respectively.

These results alone cannot permit to conclude that basal cleavage or pyramidal $\langle c+a\rangle$ cleavage, is reponsible for the material failure. However, magnesium alloys fracture mode under the conditions of temperature $\left(0.33 T_{m}\right)$ and normalized stress $\left(\sigma / E \sim 6 \times 10^{-3}\right.$ ) examined in the present paper is of the mixed mode type "cleavage 3/ductile" or "semibrittle intergranular fracture" (Gandhi and Ashby, 1979), as substantial plastic strain precedes cleavage. The cleavage planes vary for different HCP metals. Yoo (1981) calculated the ratio between the critical fracture stresses in basal and prismatic planes for a number of HCP metals. He found out that basal planes are clearly the most preferred cleavage planes in $\mathrm{Zn}$ (Yoo, 1981; Hughes et al., 2007), whereas prismatic planes are favored in Ti and Zr. Basal and prismatic planes are, respectively, 


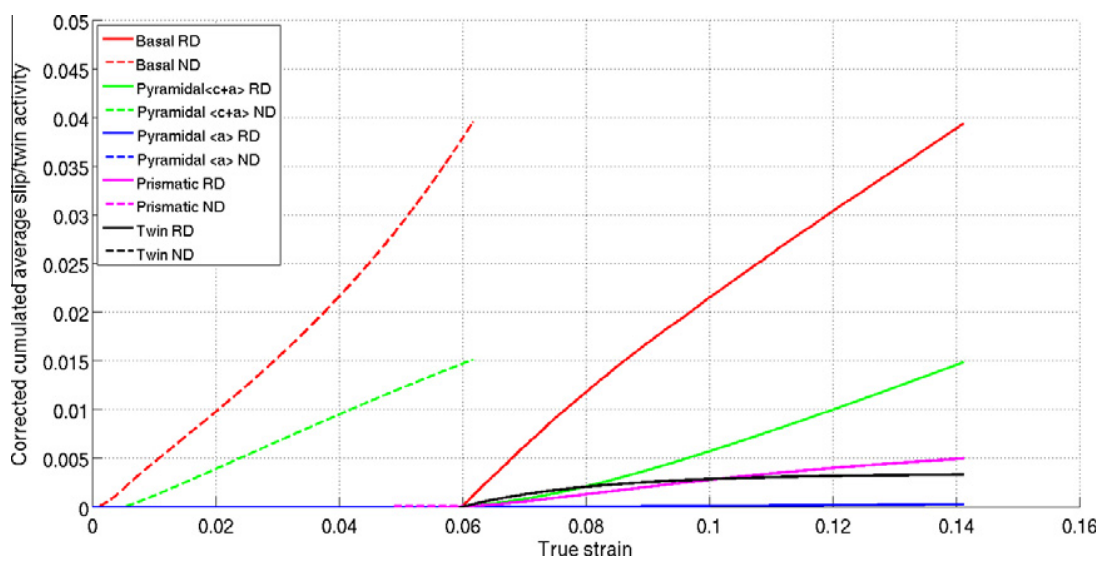

Fig. 9. Corrected cumulated average slip/twin activity for both cases of compression: along RD and along ND.

those with the smallest CRSS in those metals. Magnesium is presented by Yoo (1981) as an intermediate case. However, since basal slip is the most active deformation mode, it seems logical that cleavage is favored in basal planes. In fact, it has been reported earlier (Couling et al., 1959) that Mg sheets rolled at room temperature fail along bands formed by grains in which the basal planes are parallel to the band plane. The easiness of cleavage along basal planes has also been verified in an AZ31 alloy by Somekawa and Mukai (2005). We thus can conclude that basal cleavage is responsible for the material failure.

As a conclusion, these results suggest: (a) that sample failure is directly related to an excess of basal activity in agreement with experimental observations, probably primarily due to the formation of a shear zone along the $\langle 0001\rangle$ direction leading eventually to material failure; (b) that when the compression axis is preferably oriented along ND, pyramidal $\langle c+a\rangle$ and basal slip activities follow a very similar pattern, working collaboratively in the same proportion; (c) and finally, that the final failure is in any case independent of the other slip system activity (pyramidal $\langle a\rangle$ and prismatic) and more importantly of the twin activity.

\subsection{Validation}

In the following, we complement the previous study by using the model on a third configuration: plane strain compression along RD, constraining along TD. To this end, a specific die made of hardened stainless steel was designed for such purpose. In order to minimize friction effects, the sample surfaces were lubricated using Teflon tape. The deformation rate was identical to the previous tests $\left(10^{-4} \mathrm{~s}^{-1}\right)$.

The experiments showed a relatively important variability and a total of four (instead of three) tests was used for the final averaged stress-strain curve. The experimental stress-strain curve (with its errorbars) and the numerical one are given in Fig. 10. The four stages used in this figure are given in Table 5.

The two stress-strain curves both present an earlier point of inflection, higher hardening rates and higher stress values when compared to their respective uniaxial RD compression counterpart (see Fig. 3). Additionally, the two curves seem to

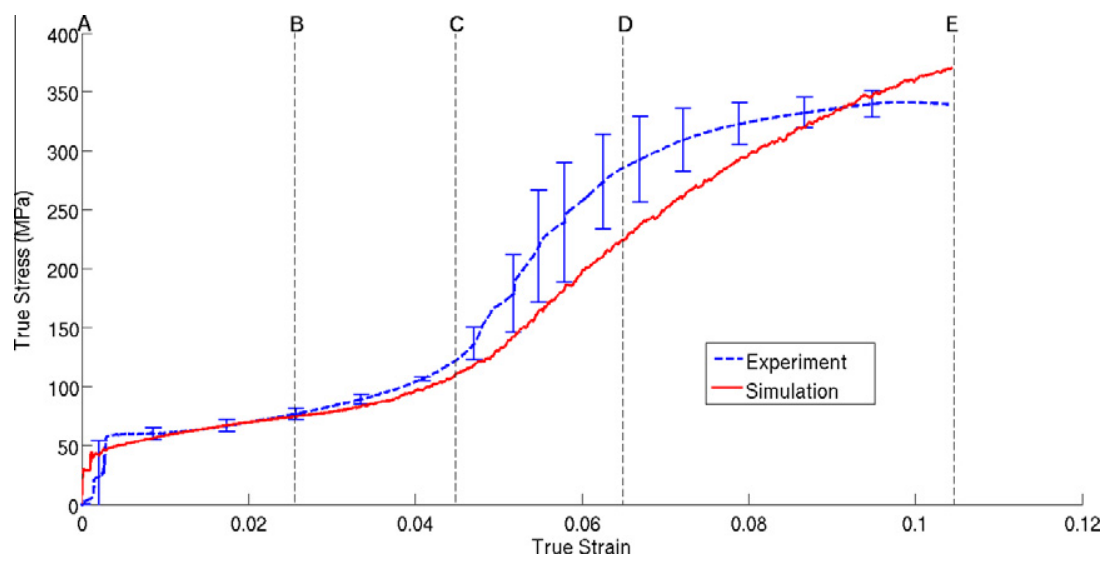

Fig. 10. Experimental and numerical stress-strain curves for the plane strain compression along RD, constrained along TD. 
Table 5

Transition strain between regions for the plane strain compression casw.

\begin{tabular}{lllll}
\hline $\mathrm{A}$ & $\mathrm{B}$ & $\mathrm{C}$ & $\mathrm{D}$ & $\mathrm{E}$ \\
\hline $0 \%$ & $2.5 \%$ & $4.5 \%$ & $6.5 \%$ & $10.3 \%$ \\
\hline
\end{tabular}

deviate between Stages C and E, incidentally corresponding to the portion of the experimental curve with the most important variability. In view of this, the simulation captures the experimental behavior relatively well.

\subsubsection{Texture evolution and slip/twin activities}

The comparison of the $\{0001\}$ texture between experiment and simulation for these different stages, and the overall slip/ twin activity are given in Figs. 11 and 12, respectively.

The pole figure evolution is relatively well caught by the simulation, with the same delay in the crystal rotation as was previously observed, see Fig. 4 and Section 4.1. Furthermore, even accounting for the different strain-to-failure, a comparison between Fig. 5(b) and Fig. 12 exhibits a very similar evolution of twin and basal slip activity (as well as pyramidal $\langle a\rangle$ which remains almost inexistent), but weaker contribution of pyramidal $\langle c+a\rangle$ and earlier contribution of prismatic, implying that prismatic slip is taking over part of the pyramidal $\langle c+a\rangle$ contribution under plane strain conditions, when compared to uniaxial.

\subsubsection{Fracture mechanisms}

Finally, the fracture criterion proposed in Section 4.2 is tested here for the new configuration. The corrected cumulated average slip/twin activity based on the methodology described earlier is shown in Fig. 13.

Note that the experimental curves were averaged up to the smallest strain-to-failure (10.4\%). However, because of the important variability of the experimentally observed strains-to-failure, which here were spanning a total of $2.6 \%$ (10.4\%, $10.9 \%, 11.2 \%, 11.6 \%$ and $13 \%$ ), the simulation could possibly be extended up to $13 \%$. As a consequence, the results in Fig. 13 were run up to $13 \%$.

As hinted by Fig. 12, Fig. 13 exhibits a lower pyramidal $\langle c+a\rangle$ cumulated average activity than in Fig. 9, but a higher prismatic activity. The basal activity, on the contrary, is very similar. More importantly, the failure cumulated average basal activity threshold of $\sim 0.04$, as defined in Section 4.2 , is reached within the strain-to-failure range of $10.4 \%-13 \%$. On the

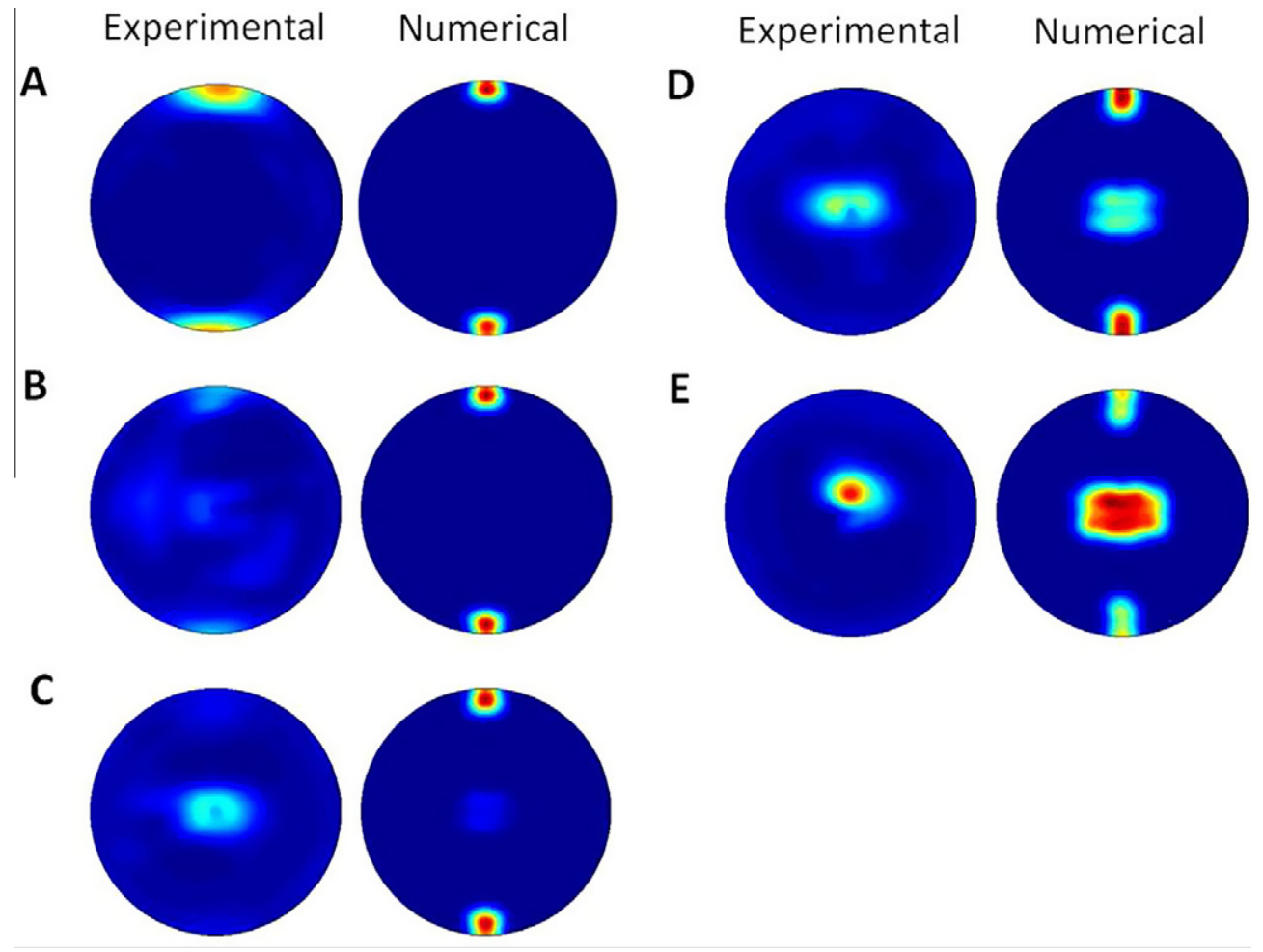

Fig. 11. Comparison between $\{0001\}$ experimental and numerical textures at deformation state A, B, C, D and E for the plane strain compression along RD, constrained along TD. 


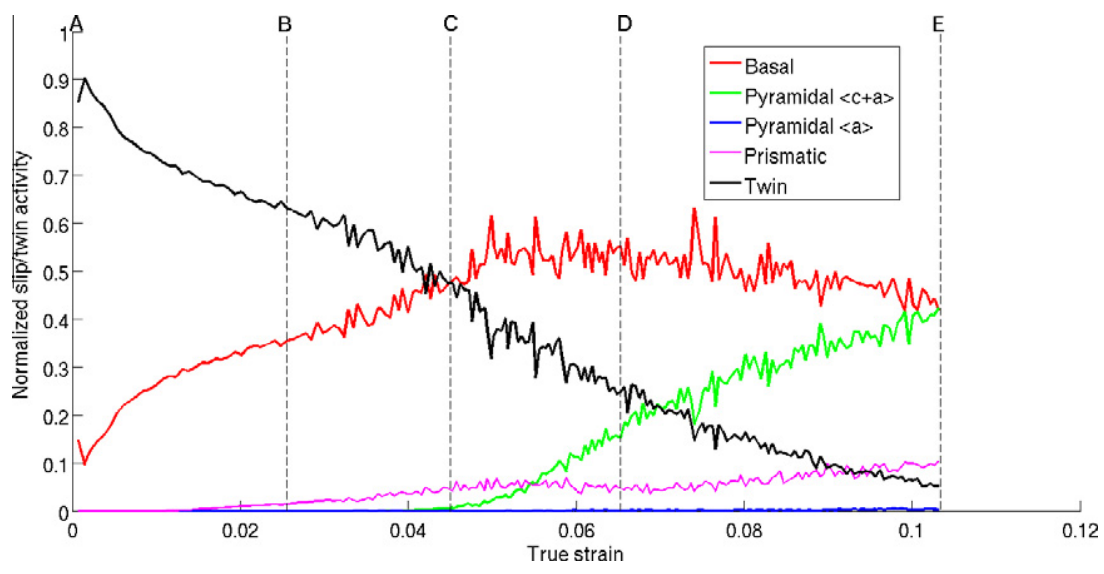

Fig. 12. Normalized slip/twin activity for the plane strain compression along RD, constrained along TD.

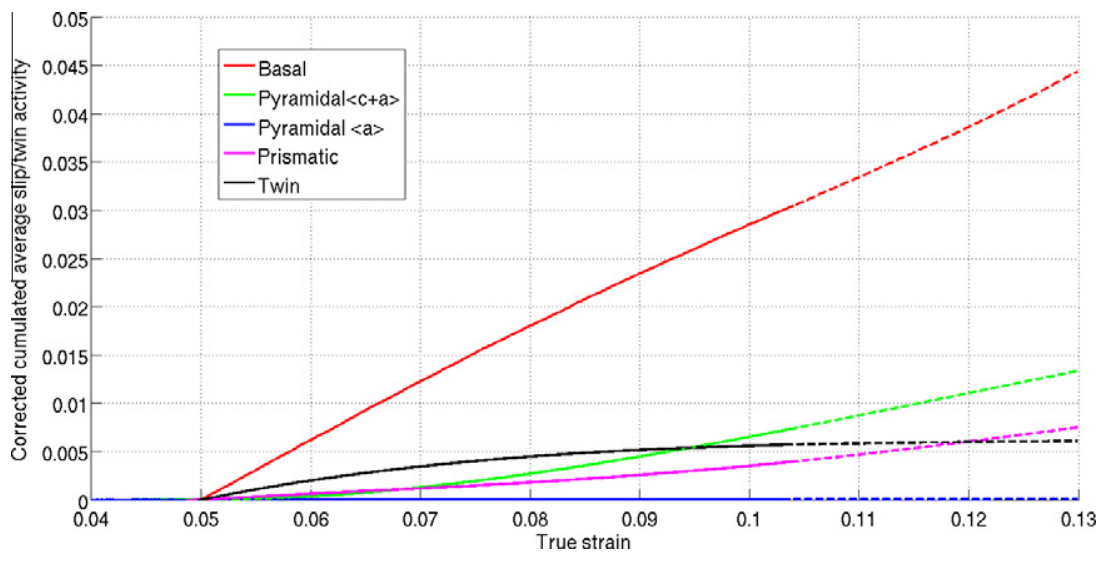

Fig. 13. Corrected cumulated average slip/twin activity for the plane strain compression along RD, constrained along TD; the dash line corresponds to the acceptable range of values for the strain-to-failure.

contrary, the pyramidal $\langle c+a\rangle$ threshold of 0.015 is not reached. This further validates the fracture threshold based on basal activity defined and discussed earlier.

\section{Conclusion}

A crystal plasticity continuum model aimed at fully describing the intrinsic deformation mechanisms between slip and twin systems has been developed. An experimental campaign consisting of a set of uniaxial and plane strain compression tests at room temperature and quasi-static strain rate, as well as an exhaustive analysis and examination of the crystallographic texture at different stages of deformation of the alloy AZ31B have been carried out. The model has then been calibrated and validated against these tests. The flexibility of the overall model was demonstrated by casting light on an experimental controversy on the role of the pyramidal slip $\langle c+a\rangle$ versus compression twinning in the late stage of polycrystalline deformation. Finally, a macroscopic failure criterion based on basal activity has been shown to accurately describe the failure of materials in what would thus be a shear zone along the $\langle 0001\rangle$ direction eventually leading to material failure. This criterion seems furthermore to be independent of the twin activity but tightly linked to pyramidal $\langle c+a\rangle$ and prismatic activities.

Finally, future work will account for multiple elements per grain, thus correcting the inability of the current model to capture the progressive twin rotation within the grain. This effort should participate in solving issue related to the delay observable in the pole figures.

\section{Acknowledgements}

The authors are grateful to Prof. Lallit Anand at the Massachusetts Institute of Technology for supplying for their research the original VUMAT for rate-independent crystal plasticity for HCP materials written by Staroselsky (1998), Staroselsky and 
Anand (2003). The VUMAT used in this work is a modified and extended version of this subroutine. The authors are also grateful to Prof. Ron Armstrong for very productive discussions. A.F., T.P. and A.J. would like to thank the vehicle interior manufacturer, Grupo Antolin Ingenieria, S.A., within the framework of the project MAGNO2008-1028-CENIT Project funded by the Spanish Ministry. Funding from the ESTRUMAT-S2009/MAT-1585 grant (Madrid Regional Government) is acknowledged. The technicians of the CAI Difracción de rayos X, of the Complutense University in Madrid, are sincerely thanked for their kind assistance. A.J. also acknowledges support from the Juan de la Cierva grant from the Spanish Ministry of Science and Innovation and from the Amarout grant from the European Union. Y.W. acknowledges financial support from Chinese Academy of Sciences for the "Hundred Talent Program" and NSFC \#11021262.

\section{References}

Agnew, S., Duygulu, O., 2005. Plastic anisotropy and the role of non-basal slip in magnesium alloy AZ31B. International Journal of Plasticity 21 (6), 11611193.

Agnew, S., Yoo, M., Tomé, C., 2001. Application of texture simulation to understanding mechanical behavior of Mg and solid solution alloys containing Li or Y. Acta Materialia 49 (20), 4277-4289.

Agnew, S., Tomé, C., Brown, D., Holden, T., Vogel, S., 2003. Study of slip mechanisms in a magnesium alloy by neutron diffraction and modeling. Scripta Materialia 48 (8), 1003-1008.

Al-Samman, T., Gottstein, G., 2008. Room temperature formability of a magnesium AZ31 alloy: examining the role of texture on the deformation mechanisms. Materials Science and Engineering A 488 (1-2), 406-414.

Anand, L., 2004. Single-crystal elasto-viscoplasticity: application to texture evolution in polycrystalline metals at large strains. Computer Methods in Applied Mechanics and Engineering 193, 5359-5383.

Anand, L., Kothari, M., 1996. A computational procedure for rate-independent crystal plasticity. Journal of the Mechanics and Physics of Solids 44 (4), 525558.

Armstrong, R., Walley, S., 2008. High strain rate properties of metals and alloys. International Materials Reviews 53 (3), $105-128$.

Bachmann, F., Hielscher, R., Schaeben, H., 2010. Texture analysis with MTEX - free and open source software toolbox. Solid State Phenomena 160, 63-68. Available from: <http://code.google.com/p/mtex/>

Ball, E., Prangnell, P., 1994. Tensile-compressive yield asymmetries in high strength wrought magnesium alloys. Scripta Metallurgica et Materialia 31 (2), $111-116$.

Bamberger, M., Dehm, G., 2008. Trends in the development of new Mg alloys. Annual Review of Materials Research 38, $505-533$.

Barnett, M., 2001. Influence of deformation conditions and texture on the high temperature flow stress of magnesium AZ31. Journal of Light Metals 1 (3), 167-177.

Barnett, M., 2003. A taylor model based description of the proof stress of magnesium AZ31 during hot working. Metallurgical and Materials Transactions A 34 (9), 1799-1806.

Barnett, M., 2007. Twinning and the ductility of magnesium alloys. Part I: "tension” twins. Materials Science and Engineering A 464 (1-2), 1-7.

Barnett, M., Keshavarz, Z., Beer, A., Atwell, D., 2004a. Influence of grain size on the compressive deformation of wrought Mg3Al-1Zn. Acta Materialia 52 (17), 5093-5103.

Barnett, M., Nave, M., Bettles, C., 2004b. Deformation microstructures and textures of some cold rolled Mg alloys. Materials Science and Engineering A 386 $(1-2), 205-211$.

Bornert, M., Masson, R., Ponte-Castañeda, P., Zaoui, A., 2001. Second-order estimates for the effective behaviour of viscoplastic polycrystalline materials. Journal of the Mechanics and Physics of Solids 49, 2737-2764.

Chin, G., Mammel, W., 1970. Competition among basal, prism, and pyramidal slip modes in HCP metals. Metallurgical Transactions 1, 357-361.

Chino, Y., Kimura, K., Mabuchi, M., 2008. Twinning behavior and deformation mechanisms of extruded AZ31 Mg alloy. Materials Science and Engineering A 486 (1-2), 481-488.

Choi, S.-H., Kim, D., Lee, H., Shin, E., 2010a. Simulation of texture evolution and macroscopic properties in Mg alloys using the crystal plasticity finite element method. Materials Science and Engineering A 527 (4-5), 1151-1159.

Choi, S.-H., Kim, D., Park, S., You, B., 2010b. Simulation of stress concentration in Mg alloys using the crystal plasticity finite element method. Acta Materialia $58,320-329$

Cizek, P., Barnett, M., 2008. Characteristics of the contraction twins formed close to the fracture surface in Mg-3Al-1Zn alloy deformed in tension. Scripta Materialia 59 (9), 959-962.

Couling, S., Pashak, J., Sturkey, L., 1959. Unique deformation and aging characteristics of certain magnesium-base alloys. Transactions of the American Society of Metals 51, 94-107.

Couret, A., Caillard, D., 1985. An in situ study of prismatic glide in magnesium-I. The rate controlling mechanism. Acta Metallurgica 33 (8), 1447-1454.

Cuitiño, A., Ortiz, M., 1993. Computational modelling of single crystals. Modelling and Simulation in Materials Science and Engineering 1 (3), $225-263$.

Danas, K., Deshpande, V., Fleck, N., 2010. Compliant interfaces: a mechanism for relaxation of dislocation pile-ups in a sheared single crystal. International Journal of Plasticity 26 (12), 1792-1805.

Dassault Systèmes, 2010. Abaqus/Explicit. Available from: <http://www.simulia.com/>.

del Valle, J., Ruano, O., 2007. Separate contributions of texture and grain size on the creep mechanisms in a fine-grained magnesium alloy. Acta Materialia 55 (2), 455-466.

del Valle, J., Pérez-Prado, M., Ruano, O., 2005. Deformation mechanisms responsible for the high ductility in a Mg AZ31 alloy analyzed by electron backscattered diffraction. Metallurgical and Materials Transactions A 36 (6), 1427-1438.

Easton, M., Beer, A., Barnett, M., Davies, C., Dunlop, G., Durandet, Y., Blacket, S., Hilditch, T., Beggs, P., 2008. Magnesium alloy applications in automotive structures. JOM Journal of the Minerals, Metals and Materials Society 60 (11), 57-62.

Fernández, A., 2009. Simulacíon numérica del comportamiento mecánico de la aleación de magnesio AZ31B, Undergraduate Thesis, Polytechnic University of Madrid.

Galiyev, A., Sitdikov, O., Kaibyshev, R., 2003. Deformation behavior and controlling mechanisms for plastic flow of magnesium and magnesium alloy. Materials Transactions 4, 426-435.

Gandhi, C., Ashby, M., 1979. Fracture mechanism maps for materials which cleave: f.c.c., b.c.c., and h.c.p. metals and ceramics. Acta Metallurgica 27, 15651602.

Gao, Y., Liu, Z., You, X., Zhuang, Z., 2010. A hybrid multiscale computational framework of crystal plasticity at submicron scales. Computational Materials Science 49 (3), 672-681.

Gehrmann, R., Frommert, M., Gottstein, G., 2005. Texture effects on plastic deformation of magnesium. Materials Science and Engineering A 395 (1-2), $338-$ 349.

Gilormini, P., Nebozhyn, M., Ponte-Castañeda, P., 2001. Accurate estimates for the creep behavior of hexagonal polycrystals. Acta Materialia 49, $329-337$. Graff, S., 2007. Micromechanical modeling of the deformation of HCP metals. Ph.D. thesis, Technischen Universität Berlin/ GKSS Forschungszentrum.

Graff, S., Brocks, W., Steglich, D., 2007. Yielding of magnesium: from single crystal to polycrystalline aggregates. International Journal of Plasticity 23, 19571978. 
Groh, S., Marin, E., Horstemeyer, M., Zbib, H., 2009. Multiscale modeling of the plasticity in an aluminum single crystal. International Journal of Plasticity 25 , $1456-1473$.

Houtte, P.V., 1978. Simulation of the rolling and shear texture of brass by the taylof theory adapted for mechanical twinning. Acta Metallurgica 26 (4), 591604.

Houtte, P.V., Kanjarla, A., Bael, A.V., Seefeldt, M., Delannay, L., 2006. Multiscale modelling of the plastic anisotropy and deformation texture of polycrystalline materials. European Journal of Mechanics A/Solids 25, 634-648.

Hughes, G., Smith, G., Flewitt, P., Crocker, A., 2007. The brittle fracture of polycrystalline zinc. Proceedings of the Royal Society A 463, $2129-2151$.

Hutchinson, B., Barnett, M., Ghaderi, A., Cizek, P., Sabirov, I., 2009. Deformation modes and anisotropy in magnesium alloy AZ31. International Journal of Materials Research, 556-563.

Ion, S., Humphreys, F., White, S., 1982. Dynamic recrystallization and the development of microstructure during the high temperature deformation of magnesium. Acta Metallurgica 30 (10), 1909-1919.

Izadbakhsh, A., Inal, K., Mishra, R., Niewczas, M., 2011. New crystal plasticity constitutive model for large strain deformation in single crystals of magnesium. Computational Materials Science 50 (7), 2185-2202.

Jain, A., Agnew, S., 2007. Modeling the temperature dependent effect of twinning on the behavior of magnesium alloy AZ31B sheet. Materials Science and Engineering A 462, 29-36.

Jain, A., Duygulu, O., Brown, D., Tomé, C., Agnew, S., 2008. Grain size effects on the tensile properties and deformation mechanisms of a magnesium alloy, AZ31B, sheet. Materials Science and Engineering A 486 (1-2), 545-555.

Jérusalem, A., Dao, M., Suresh, S., Radovitzky, R., 2008. Three-dimensional model of strength and ductility of polycrystalline copper containing nanoscale twins. Acta Materialia 56, 4647-4657.

Kadiri, H.E., Oppedal, A., 2010. A crystal plasticity theory for latent hardening by glide twinning through dislocation transmutation and twin accommodation effects. Journal of the Mechanics and Physics of Solids 58, 613-624.

Kelley, E., Hosford, W., 1968a. The deformation characteristics of textured magnesium. Transactions of the metallurgical society of AIME 242, 654-661.

Kelley, E., Hosford, W., 1968b. Plane strain compression of magnesium and magnesium alloy crystals. Transactions of the metallurgical society of AIME 242 , 5-13.

Keshavarz, Z., Barnett, M., 2006. EBSD analysis of deformation modes in Mg-3Al-1Zn. Scripta Materialia 55 (10), 915-918.

Khan, A., Pandey, A., Gnäupel-Herold, T., Mishra, R., 2011. Mechanical response and texture evolution of AZ31 alloy at large strains for different strain rates and temperatures. International Journal of Plasticity 27, 688-706.

Knezevic, M., Kalidindi, S., Mishra, R., 2008. Delineation of first-order closures for plastic properties requiring explicit consideration of strain hardening and crystallographic texture evolution. International Journal of Plasticity 24, 327-342.

Knezevic, M., Levinson, A., Harris, R., Mishra, R., Doherty, R., Kalidindi, S., 2010. Deformation twinning in AZ31: influence on strain hardening and texture evolution. Acta Materialia 58, 6230-6242.

Kocks, U., Westlake, D., 1967. The importance of twinning for the ductility of CPH polycrystals. Transactions of the metallurgical society of AIME $239,1107-$ 1109.

Koike, J., Kobayashi, T., Mukai, T., Watanabe, H., Suzuki, M., Maruyama, K., Higashi, K., 2003. The activity of non-basal slip systems and dynamic recovery at room temperature in fine-grained AZ31B magnesium alloys. Acta Materialia 51 (7), 2055-2065.

Kuchnicki, S., Radovitzky, R., Cuitiño, A., 2008. An explicit formulation for multiscale modeling of bcc metals. International Journal of Plasticity 24 (12), 2173-2191.

Lebensohn, R., Liu, Y., Ponte-Castañeda, P., 2004. On the accuracy of the self-consistent approximation for polycrystals: comparison with full-field numerical simulations. Acta Materialia 52, 5347-5361.

Lebensohn, R., Tomé, C., Ponte-Castañeda, P., 2007. Self-consistent modelling of the mechanical behaviour of viscoplastic polycrystals incorporating intragranular field fluctuations. Philosophical Magazine 87 (28), 4287-4322.

Lee, E., 1969. Elastic plastic deformation at finite strain. Journal of Applied Mechanics 36, 1-6.

Lee, M., Lim, H., Adams, B., Hirth, J., Wagoner, R., 2010. A dislocation density-based single crystal constitutive equation. International Journal of Plasticity 26 , 925-938.

Lévesque, J., Inal, K., Neale, K., Mishra, R., 2010. Numerical modeling of formability of extruded magnesium alloy tubes. International Journal of Plasticity 26 , 65-83.

Liu, Y., Gilormini, P., Ponte-Castañeda, P., 2003. Variational self-consistent estimates for texture evolution in viscoplastic polycrystals. Acta Materialia 51, 5425-5437.

Liu, Z., Zhuang, Z., Liu, X., Zhao, X., Zhang, Z., 2011. A dislocation dynamics based higher-order crystal plasticity model and applications on confined thin-film plasticity. International Journal of Plasticity 27 (2), 201-216.

Lou, X., Li, M., Boger, R., Agnew, S., Wagoner, R., 2007. Hardening evolution of AZ31B Mg sheet. International Journal of Plasticity 23 (1), $44-86$.

Mayama, T., Aizawa, K., Tadano, Y., Kuroda, M., 2009. Influence of twinning deformation and lattice rotation on strength differential effect in polycrystalline pure magnesium with rolling texture. Computational Materials Science 47, 448-455.

Mayeur, J., McDowell, D., 2007. A three-dimensional crystal plasticity model for duplex Ti-6Al-4V. International Journal of Plasticity 23, 1457-1485.

Meza-García, E., Dobron̆, P., Bohlen, J., Letzig, D., Chmelík, F., Lukáć, P., Kainer, K., 2007. Deformation mechanisms in an AZ31 cast magnesium alloy as investigated by the acoustic emission technique. Materials Science and Engineering A 462 (1-2), 297-301.

Miehe, C., Schröder, J., Schotte, J., 1999. Computational homogenization analysis in finite plasticity simulation of texture development in polycrystalline materials. Computer Methods in Applied Mechanics and Engineering 171 (3-4), 387-418.

Miller, R., Tadmor, E., 2002. The quasicontinuum method: overview, applications and current directions. Journal of Computer-Aided Materials Design 9 (3), 103-239.

Mordike, B., Ebert, T., 2001. Magnesium: properties - applications - potential. Materials Science and Engineering A 302 (1), 37-45

Munroe, N., Tan, X., 1997. Orientation dependence of slip and twinning in HCP metals. Scripta Materialia 36 (12), 1383-1386.

Nave, M., Barnett, M., 2004. Microstructures and textures of pure magnesium deformed in plane-strain compression. Scripta Materialia 9, $881-885$.

Neil, C., Agnew, S., 2009. Crystal plasticity-based forming limit prediction for non-cubic metals: Application to Mg alloy AZ31B. International Journal of Plasticity 25, 379-398.

Obara, T., Yoshinga, H., Morozumi, S., 1973. 112̄2 $\langle 1 \overline{1} 23\rangle$ slip system in magnesium. Acta Metallurgica 21, 845-853.

Prakash, A., Weygand, S., Riedel, H., 2009. Modeling the evolution of texture and grain shape in Mg alloy AZ31 using the crystal plasticity finite element method. Computational Materials Science 45 (3), 744-750.

Proust, G., Tomé, C., Jain, A., Agnew, S., 2009. Modeling the effect of twinning and detwinning during strain-path changes of magnesium alloy AZ31. International Journal of Plasticity 25, 861-880.

Rice, J., 1971. Inelastic constitutive relations for solids: an internal-variable theory and its application to metal plasticity. Journal of the Mechanics and Physics of Solids 19 (6), 433-455.

Rossiter, J., Brahme, A., Simha, M., Inal, K., Mishra, R., 2010. A new crystal plasticity scheme for explicit time integration codes to simulate deformation in 3D microstructures: Effects of strain path, strain rate and thermal softening on localized deformation in the aluminum alloy 5754 during simple shear. International Journal of Plasticity 26 (12), 1702-1725.

Roters, F., Eisenlohr, P., Hantcherli, L., Tjahjanto, D., Bieler, T., Raabe, D., 2010. Overview of constitutive laws, kinematics, homogenization and multiscale methods in crystal plasticity finite-element modeling: theory, experiments, applications. Acta Materialia 58 (4), 1152-1211.

Segurado, J., LLorca, J., Romero, I., 2007. Computational issues in the simulation of two-dimensional discrete dislocation mechanics. Modelling and Simulation in Materials Science and Engineering 15 (4), S361-S376. 
Serra, A., Bacon, D., 1996. A new model for $\{10 \overline{1} 2\}$ twin growth in HCP metals. Philosophical Magazine A 73 (2), $333-343$.

Shaffer, J., Knezevic, M., Kalidindi, S., 2010. Building texture evolution networks for deformation processing of polycrystalline fcc metals using spectral approaches: applications to process design for targeted performance. International Journal of Plasticity 26, 1183-1194.

Shen, F., Zhou, J., Liu, Y., Zhu, R., Zhang, S., Wang, Y., 2010. Deformation twinning mechanism and its effects on the mechanical behaviors of ultrafine grained and nanocrystalline copper. Computational Materials Science 49 (2), 226-235.

Somekawa, H., Mukai, T., 2005. Effect of texture on fracture toughness in extruded AZ31 alloy. Scripta Materialia 53, 541-545.

Staroselsky, A., 1998. Crystal plasticity due to slip and twinning. Ph.D. thesis, Massachusetts Institute of Technology.

Staroselsky, A., Anand, L., 2003. A constitutive model for HCP materials deforming by slip and twinning: application to magnesium alloy AZ31B. International Journal of Plasticity 19 (10), 1843-1864.

Sung, J., Kim, J., Wagoner, R., 2010. A plastic constitutive equation incorporating strain, strain-rate, and temperature. International Journal of Plasticity 26 (12), 1746-1771.

Tang, W., Zhang, S., Peng, Y., Li, D., 2009. Simulation of magnesium alloy AZ31 sheet during cylindrical cup drawing with rate independent crystal plasticity finite element method. Computational Materials Science 46 (2), 393-399.

Taylor, G., 1938. Plastic strain in metals. Journal of the Institute of Metals 62, 307-324.

Thamburaja, P., 2010. A finite-deformation-based phenomenological theory for shape-memory alloys. International Journal of Plasticity 26, $1195-1219$.

Ulacia, I., Dudamell, N., Gálvez, F., Yid, S., Pérez-Prado, M., Hurtado, I., 2010. Mechanical behavior and microstructural evolution of a Mg AZ31 sheet at dynamic strain rates. Acta Materialia 58 (8), 2988-2998.

Vagaralia, S., Langdon, T., 1981. Deformation mechanisms in h.c.p. metals at elevated temperatures-I. Creep behavior of magnesium. Acta Metallurgica 29 (12), 1969-1982.

Valle, J.D., Ruano, O., 2009. Effect of annealing treatments on the anisotropy of a magnesium alloy sheet processed by severe rolling. Materials Letters 63 (17), 1551-1554.

Wang, J., Hirth, J., Tomé, C., 2009a. (1012) twinning nucleation mechanisms in hexagonal-close-packed crystals. Acta Materialia 57 (18), $5521-5530$.

Wang, Z., Beyerlein, I., LeSar, R., 2009b. Plastic anisotropy in fcc single crystals in high rate deformation. International Journal of Plasticity 25, 26-48.

Wang, H., Raeisinia, B., Wu, P., Agnew, S., Tomé, C., 2010. Evaluation of self-consistent polycrystal plasticity models for magnesium alloy AZ31B sheet. International Journal of Solids and Structures 47, 2905-2917.

Watanabe, H., Ishikawa, K., 2009. Effect of texture on high temperature deformation behavior at high strain rates in a Mg3Al1Zn alloy. Materials Science and Engineering A 523, 304-311.

Watanabe, H., Tsutsui, H., Mukai, T., Kohzu, M., Tanabe, S., Higashi, K., 2001. Deformation mechanism in a coarse-grained Mg-Al-Zn alloy at elevated temperatures. International Journal of Plasticity 17 (3), 387-397.

Watanabe, I., Setoyama, D., Iwata, N., Nakanishi, K., 2010. Characterization of yielding behavior of polycrystalline metals with single crystal plasticity based on representative characteristic length. International Journal of Plasticity 26, 570-585.

Wonsiewicz, B., Backofen, W., 1967. Plasticity of magnesium crystals. Transactions of the metallurgical society of AIME $239,1422-1431$.

Yi, S., Davies, C., Brokmeier, H., Bolmaro, R., Kainer, K., Homeyer, J., 2006. Deformation and texture evolution in AZ31 magnesium alloy during uniaxial loading. Acta Materialia 54 (3), 549-562.

Yoo, M., 1981. Slip, twinning, and fracture in hexagonal close-packed metals. Metallurgical Transactions 12A, 409-418.

Yue, L., Zhang, H., Li, D., 2010. A closer look at the local responses of twin and grain boundaries in Cu to stress at the nanoscale with possible transition from the $\mathrm{P}-\mathrm{H}$ to the inverse P-H relation. Acta Materialia 58 (7), 2677-2684.

Zamiri, A., Pourboghrat, F., 2010. A novel yield function for single crystals based on combined constraints optimization. International Journal of Plasticity 26, $731-746$.

Zbib, H., Rhee, M., Hirth, J., 1998. On plastic deformation and the dynamics of 3D dislocations. International Journal of Mechanical Sciences 40 (2-3), 113127.

Zelin, M., Yang, H., Valiev, R., Mukherjee, A., 1992. Interaction of high-temperature deformation mechanisms. Metallurgical and Materials Transactions A 23 (11), 3135-3140.

Zhao, Z., Kuchnicki, S., Radovitzky, R., Cuitiño, A., 2007. Influence of in-grain mesh resolution on the prediction of deformation textures in fcc polycrystals by crystal plasticity FEM. Acta Materialia 55, 2361-2373.

Zhao, Z., Ramesh, M., Raabe, D., Cuitiño, A., Radovitzky, R., 2008. Investigation of three-dimensional aspects of grain-scale plastic surface deformation of an aluminum oligocrystal. International Journal of Plasticity 24 (12), 2278-2297. 